University of Louisville

ThinkIR: The University of Louisville's Institutional Repository

Electronic Theses and Dissertations

$12-2017$

\title{
Material properties design using simulations and experiments for powder injection molding of lead zirconate titanate (PZT).
}

\author{
Bhushan Pramod Bandiwadekar \\ University of Louisville
}

Follow this and additional works at: https://ir.library.louisville.edu/etd

Part of the Bioimaging and Biomedical Optics Commons, Biomechanical Engineering Commons, Ceramic Materials Commons, Computer-Aided Engineering and Design Commons, and the Metallurgy Commons

\section{Recommended Citation}

Bandiwadekar, Bhushan Pramod, "Material properties design using simulations and experiments for powder injection molding of lead zirconate titanate (PZT)." (2017). Electronic Theses and Dissertations. Paper 2842.

https://doi.org/10.18297/etd/2842

This Master's Thesis is brought to you for free and open access by ThinkIR: The University of Louisville's Institutional Repository. It has been accepted for inclusion in Electronic Theses and Dissertations by an authorized administrator of ThinkIR: The University of Louisville's Institutional Repository. This title appears here courtesy of the author, who has retained all other copyrights. For more information, please contact thinkir@louisville.edu. 
MATERIAL PROPERTIES DESIGN USING SIMULATIONS AND EXPERIMENTS FOR POWDER INJECTION MOLDING OF LEAD ZIRCONATE TITANATE (PZT)

\author{
By \\ Bhushan Pramod Bandiwadekar \\ B.E Mechanical, University of Mumbai, 2015 \\ PGDTD\&CC, MSME, Indo German Tool Room, 2016
}

\begin{abstract}
A Thesis
Submitted to the faculty of the

J. B. Speed School of Engineering of University of Louisville

In Partial Fulfillment of the Requirements

for the Degree of

Master of Science

in Mechanical Engineering

Department of Mechanical Engineering

University of Louisville

Louisville, Kentucky
\end{abstract}

December 2017 
Copyright 2017 by Bhushan Pramod Bandiwadekar

All rights reserved 

MATERIAL PROPERTIES DESIGN USING SIMULATIONS AND EXPERIMENTS FOR POWDER INJECTION MOLDING OF LEAD ZIRCONATE TITANATE (PZT)

\author{
By \\ Bhushan Pramod Bandiwadekar \\ B.E Mechanical, University of Mumbai, 2015 \\ PGDTD\&CC, MSME, Indo German Tool Room, 2016
}

A Thesis Approved on

November 30, 2017

by the following Thesis Committee:

Dr. Kunal Kate

Dr. Sundar Atre

Dr. Jagannadh Satyavolu 


\section{DEDICATION}

This thesis is dedicated to my parents

Mr. Pramod Arjun Bandiwadekar

and

Mrs. Pradnya Pramod Bandiwadekar

who have given me invaluable educational opportunities 


\section{ACKNOWLEDGEMENTS}

I would first like to acknowledge the financial support from Agency for Defense Development (ADD), Korea.

I would also like to thank my thesis advisor Dr. Kunal Kate of J.B. Speed School of Engineering at University of Louisville. The door to Dr. Kunal's office was always open to me, whenever I ran into a trouble spot or had a question about my research or writing. He consistently allowed this paper to be my own work, but steered me in the right direction whenever he thought I needed it.

I would also like to thank my mentor Dr. Sundar Atre, for identifying my talent and capabilities in research and making me part of his guild, Materials Innovation Guild. As an expert himself in the field of my research, he offered me several opportunities to interact with the industry and making me part of various training programs. He always pushed me to present my research in front of an audience, be it in front of my lab mates, industry people or at a conference. His constructive critisim on my research interpretations has always lead me to work smarter and present my ideas better.

My research lab, Materials Innovation Guild, is nothing less than a corporate research centre. Each individual has her/his own expertise which makes the research group more versatile and innovative. I would like to thank my collegues, especially Harish Irrinki, Subrata Debnath, Nirupama Warrier and Paramjoth Singh to name a few, who have always been kind, helpful and supportive throughout the research. I would also like to thank our 
collaborators from Pohang University of Science and Technology, South Korea for their support and guidance.

Researchers are sometimes told, "Get a life!", and I have one, thanks to my friends Juili, Muddasir, Sonali and many more from my circle of friends for their goodwill, support and guidance through numerous tough decisions. With ambitions soaring high, I relied on them to strike a balance between work and leisure.

Last but not the least, I would like to thank my parents, Pramod A. Bandiwadekar and Pradnya P. Bandiwadekar, firstly, for bringing me into this world and instilling courage and confidence in me and secondly, for supporting my endeavors and trusting my steps towards a fulfilling career.

Bhushan Bandiwadekar 


\begin{abstract}
MATERIAL PROPERTIES DESIGN USING SIMULATIONS AND EXPERIMENTS FOR POWDER INJECTION MOLDING OF LEAD ZIRCONATE TITANATE (PZT)

Bhushan Pramod Bandiwadekar
\end{abstract}

November 30, 2017

Powder injection molding (PIM) process simulations can be performed to minimize the number of injection molding experiments by estimating material properties necessary for PIM simulations. In current work, lead zirconate titanate (PZT) powder-polymer binder feedstock was compounded for 45 vol. \% and 52 vol. \% solids loading. PIM experiments on designed micro-pillar array geometry were performed using 52 vol. \% PZT. Using PIM experiments results as basis, PIM simulations were performed on designed micro-pillar array geometries to understand the effectiveness of PIM simulations with the use of estimated feedstock properties in predicting molding behavior that have micro-features. Additionally, PIM simulations were performed to understand the defects after debinding and sintering. As the approach is to develop feedstock without measurement of feedstock properties, it is expected that the results from current work will help in reducing the number of experiments needed to obtain a defect free PIM products. 


\section{TABLE OF CONTENTS}

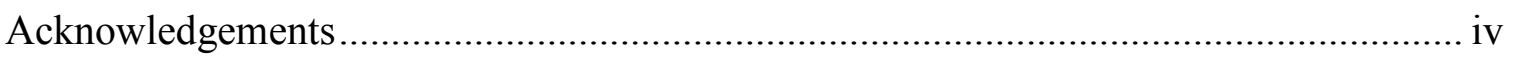

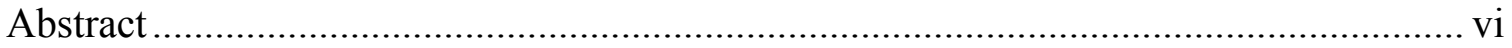

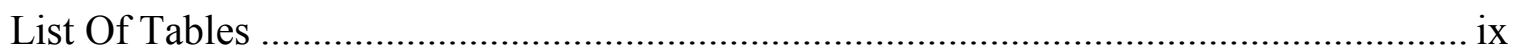

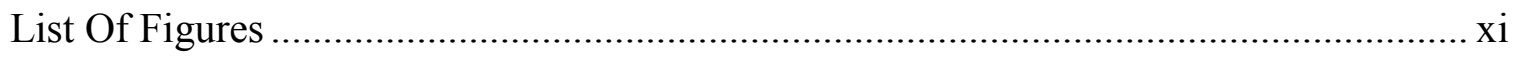

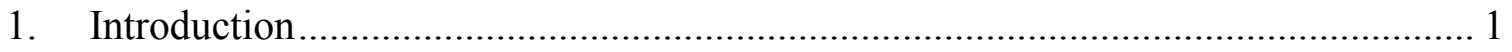

2. Influence Of Feedstock Property Estimates And Measurements On Powder Injection Molding Of Lead Zirconate Titanate (Pzt) ................................................................ 5

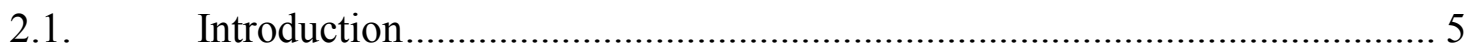

2.2. Experimental Materials And Methods .................................................... 7

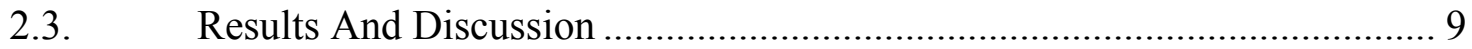

2.3.1. Estimating Properties Of Powder-Polymer Mixtures............................. 9

2.3.2. Experimental And Simulations Results.......................................... 15

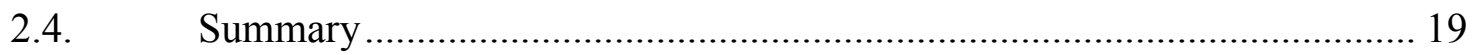

3. Influence Of Feedstock Property Estimates And Simulations On Powder Injection Molding Of Lead Zirconate Titanate (Pzt) Microarrays ................................................... 21

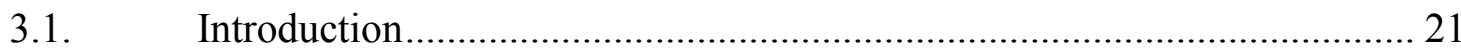

3.2. Experimental Materials And Methods ..................................................... 22

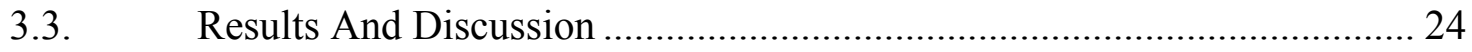

3.3.1. Estimating Material Property …………………………................. 24 
3.3.2. Experiments And Simulations ...................................................... 28

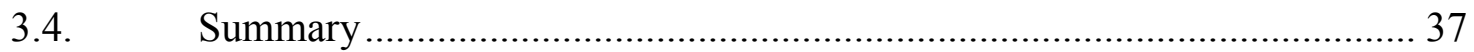

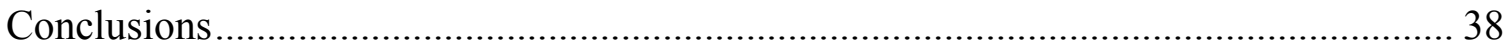

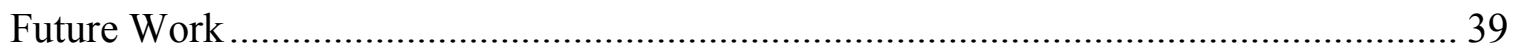

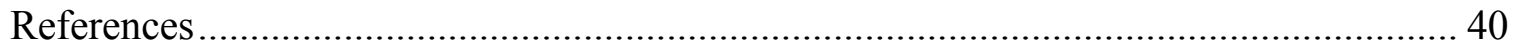

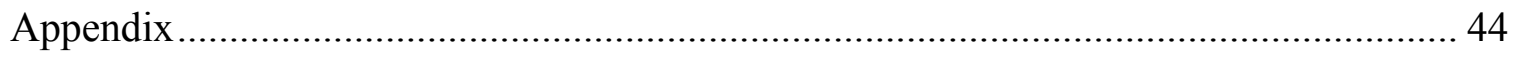

(A) Cad Models And Process Conditions For Simulations ......................................... 44

(B) Effect Of Change In Microarray Spacing ........................................................... 47

1. Mold Filling Behavior .............................................................................. 47

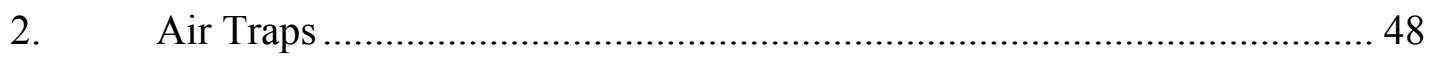

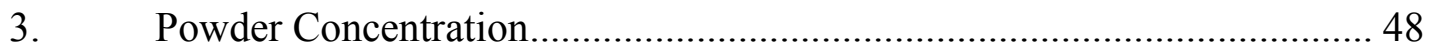

(C) Effect Of Change In Gate Location.................................................................. 49

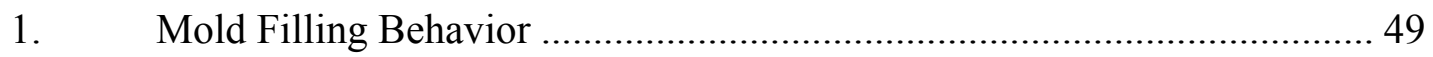

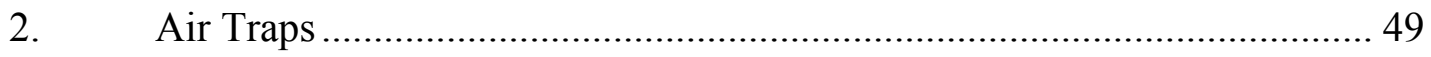

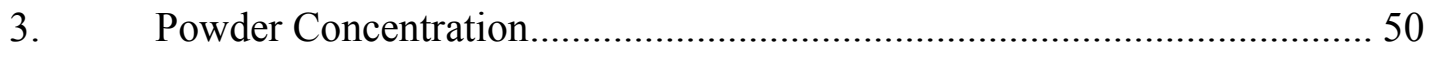

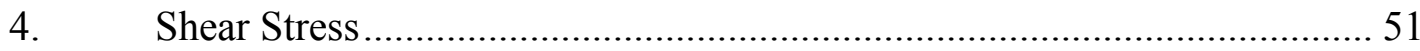

(D) Rheology Of Powder-Polymer Composite............................................................. 53

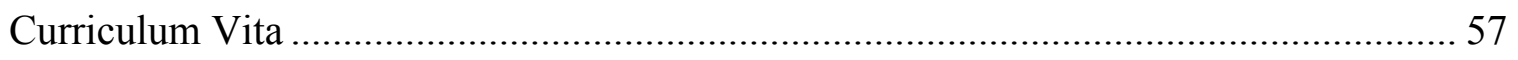




\section{LIST OF TABLES}

TABLE

PAGE

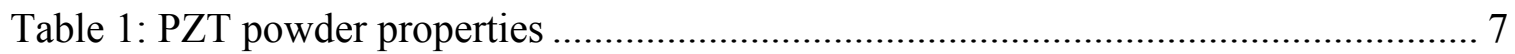

Table 2: Solid and melt densities of feedstocks with 45 vol. \% PZT powder ................. 10

Table 3: Specific heat capacity and thermal conductivity values at various temperatures

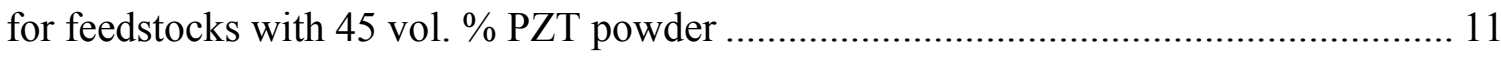

Table 4: Dual-domain Tait constants for feedstocks with 45 vol. \% PZT powder........... 12

Table 5: Cross-WLF constants for feedstocks with 45 vol. \% PZT powder ................... 14

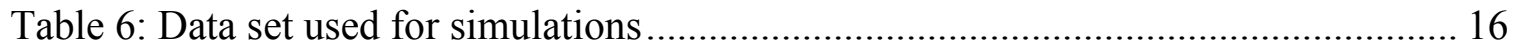

Table 7: Statistical comparison of experiments compared with simulations using estimated and hybrid material properties (a) relative error in part weight of simulations

w.r.t. experiments (b) Volumetric shrinkage (\%) of base plate .................................... 19

Table 8: Process conditions for powder injection molding ........................................ 24

Table 9: Solid and melt densities of feedstock with 52 vol. \% PZT powder................... 25

Table 10: Specific heat capacity and thermal conductivity values at various temperatures

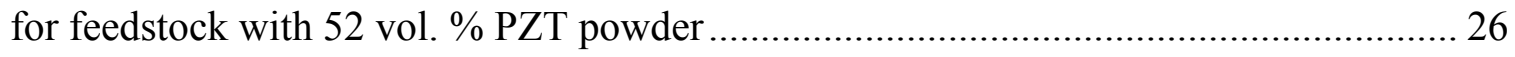

Table 11: Dual-domain Tait constants for binder and 52vol\% PZT feedstock ............... 27

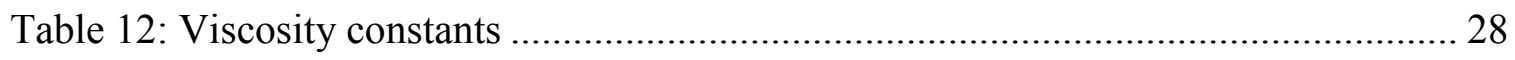

Table 13: Comparison of part weight with experiments and simulations ...................... 30

Table 14: Comparison of linear shrinkage in experiments and simulations .................... 30 


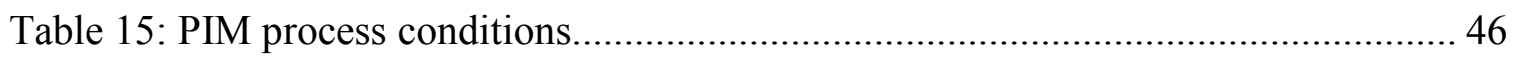

Table 16: Measured viscosity of 52 vol. \% PZT with WB50 multicomponent binder .... 53

Table 17: Measured viscosity of WB50 multicomponent binder ................................. 54 


\section{LIST OF FIGURES}

Figure 1: SEM image of PZT powder

Figure 2: Rectangular plate (a) Solidworks part file (b) Meshed with runner gate system

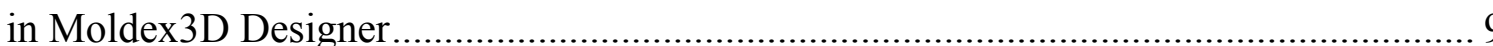

Figure 3: PVT behavior for 0, 100, and $200 \mathrm{MPa}$ pressures for 45 vol. \% PZT powder. 12 Figure 4: Comparison of viscosity with shear rate at different temperatures for 45 vol. \% PZT powder. 14

Figure 5: PIM experiment for 45 vol. \% PZT rectangular plate with 100\% filling at injection velocity $90 \mathrm{~mm} / \mathrm{s}$ and injection pressure at $40 \mathrm{MPa}$ (a) top view (b) 3D perspective view 16

Figure 6: Moldex3D simulation for $0.45 \%$ PZT base plate - $100 \%$ filled at injection velocity $90 \mathrm{~mm} / \mathrm{s}$ : (a) $30 \%$ filled in $0.025 \mathrm{~s}$, (b) $45 \%$ filled in $0.038 \mathrm{~s}$, (c) $75 \%$ filled in $0.064 \mathrm{~s}$ and (d) $100 \%$ filled in $0.085 \mathrm{~s}$

Figure 7: Evolution of simulated flow front for $0.45 \%$ PZT base plate compared with experimental results 18

Figure 8: Experiments compared with simulations using estimated and hybrid material properties - (a) Part weight of base plate (b) Volumetric shrinkage (\%) of base plate..... 18 Figure 9: Microarray geometry: SolidWorks part file ............................................... 23

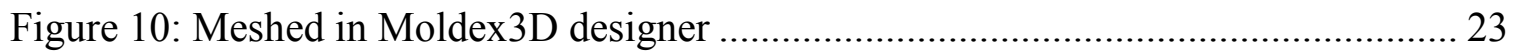


Figure 11: Sintered Microarray part

Figure 12: Mold filling behavior in microarray ...................................................... 30

Figure 13: Powder concentration of filled and packed microarray ............................... 31

Figure 14: Powder concentration within individual micro-pillars ................................ 32

Figure 15: (a) Powder concentration of micro-pillar at location A1 (b) Broken micro-

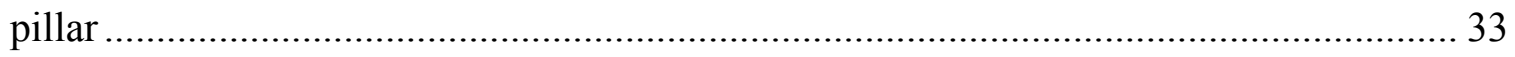

Figure 16: Temperature during filling at bottom of micro-pillar.................................. 34

Figure 17: 3D plot of temperature distribution within micro-pillar with respect to its

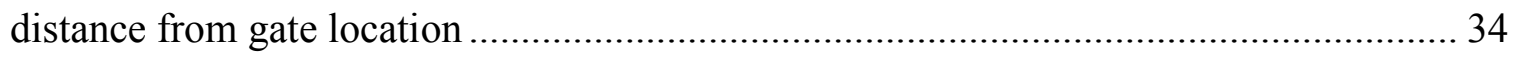

Figure 18: 3D plot of \% powder concentration with respect to its distance from gate

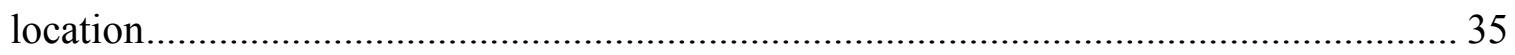

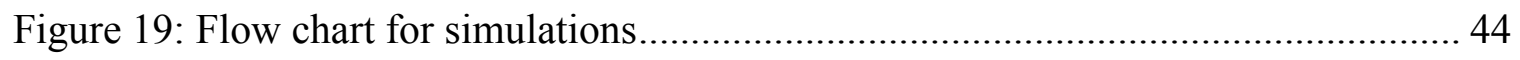

Figure 20: Microarray geometry (CAD model) with inter-pillar spacing (a) $0.7 \mathrm{~mm}$ (b)

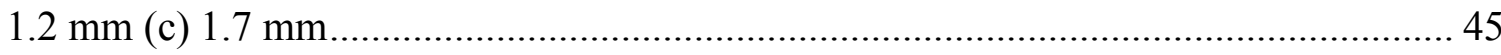

Figure 21: Bottom gate location on the mesh file (Moldex3D) ................................... 46

Figure 22: Mold filling behavior for change in microarray spacing ........................... 47

Figure 23: Air traps for change in microarray spacing .......................................... 48

Figure 24: Powder concentration for change in microarray spacing ............................. 48

Figure 25: Mold filling behavior for change in gate location .................................. 49

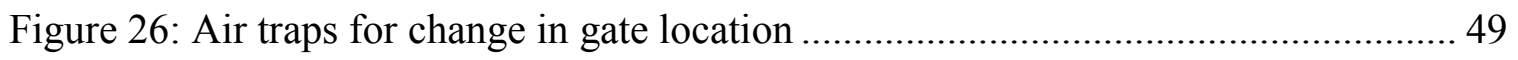

Figure 27: Comparison of air traps for different gate location ................................... 50

Figure 28: Powder concentration for change in gate location ................................. 50

Figure 29: Shear stress for $0.7 \mathrm{~mm}$ microarray spacing with bottom gate ..................... 51 
Figure 30: Shear stress for $1.2 \mathrm{~mm}$ microarray spacing with bottom gate 51

Figure 31: Shear stress for $1.7 \mathrm{~mm}$ microarray spacing with bottom gate 52

Figure 32: Measured viscosity of 52 vol. \% PZT with WB50 multicomponent binder ... 53

Figure 33: Measured viscosity of WB50 multicomponent binder................................... 54 


\section{CHAPTER 1}

\section{INTRODUCTION}

Powder Injection Molding (PIM) is the enabling technology which can be used to manufacture complex, precision and net shape components using metal or ceramics [1]. When metal is used in powder-polymer composites, the process is called Metal Injection Molding. Likewise for ceramics, the process is called Ceramic Injection Molding (CIM). CIM which is done at micron level, is often referred as Micro Ceramic Injection Molding ( $\mu \mathrm{CIM})[2]$. Small parts with complex features are mass produced at low cost using $\mu \mathrm{CIM}$ $[3]$.

Micro-structured components developed from ceramics using $\mu \mathrm{CIM}$, increase material range available in micro dimensions [4]. With this said, such enhanced products find its applications in various micro-optical or medical applications.

PIM consists of four major steps i.e. feedstock development, injection molding, debinding and sintering. Feedstock is developed by mixing selected powders and multi-component binder system in optimal proportions. This feedstock is then granulated and injection molded to get $100 \%$ filled and packed green body. The next step is to get rid of binder from the green body, thus to obtained a porous brown body. The part is then sintered at elevated 
temperature to thus obtain near net shape. Sometimes secondary processes are also carried as performed in conventional powder metallurgy [5].

Piezoelectricity can be defined as the ability of certain material to develop electric charge due to external mechanical stress. For bio-imaging application such as ultrasonic transducer, piezoelectric ceramics are been used as they offer a range of dielectric constants, large piezo electric co-efficient and high electromechanical coupling. Lead zirconate titanate, $\mathrm{Pb}\left(\mathrm{Zr}_{1-\mathrm{x}}, \mathrm{Ti}_{\mathrm{x}}\right) \mathrm{O}_{3}(\mathrm{PZT})$, has been material of choice for several decades as piezoelectric ceramic $[6,7]$.

In this particular study, lead zirconate titanate (PZT) mixed homogenous multicomponent binder is used as powder-polymer composite for CIM of microarray. PZT microarrays have been previously established with numerous applications such as nonvolatile memory devices because for their commendable ferroelectric properties; and as sensors in actuators in microelectromechanical systems (MEMS) due to its piezoelectric properties [8-10].

PZT microarrays can be fabricated with different techniques such as rod placement, dice and fill, injection molding, lost mold, tape lamination, fiber processing, co-extrusion and solid free from fabrication. From the above discussed techniques, dice and fill technique is the commercially used technique where a block of fired PZT is micro machined with a series of parallel and perpendicular cuts to form the microarrays[11]. The size of micro pillars is dependent on the accuracy of dicing saw and ability of ceramic to withstand the process. The dicing process itself is time consuming. CIM is relatively faster alternative than this commercially used technique. With CIM, a variety of rod size, shape and spacing can also be obtained [7]. But feedstock development is the crucial step in any CIM process as any defect in its formulation cannot be corrected in subsequent steps of CIM. Thus it is 
important for the feedstock to be uniform and homogeneous without any powder-binder particle segregation. Failure to obtain uniform powder concentration due to unsuitable rheological behavior of feedstock will cause to various molding defects such as distortion, cracks or voids. These defects during PIM in turn leads to non-uniform shrinkage or warping in the sintered parts $[5,12]$.

Therefore, the main goal of this study is to reduce trial and error in feedstock development by using an existing feedstock model to estimate material properties (density, viscosity, specific heat, thermal conductivity and specific volume) and validate simulations performed using estimated properties with PIM experiments. This work was funded by Agency for Defense Development, South Korea and was researched in collaboration with an international university, POSTECH, South Korea.

Various compositions of feedstock was developed and studied with various content of PZT powder and multicomponent binder. Chapter 2 studies the 45 vol. \% PZT-binder composition. Material properties of the feedstock are estimated and Moldex3D simulations are performed. The mold filling behavior, part weight and shrinkage is studied for a flat plate geometry. The results of the simulations are validated using experiments. Chapter 2 was presented as a conference paper for POWDERMET2017 conference, held in Las Vegas. This work was published in Advances in Powder Metallurgy \& Particulate Materials 2017 and Powder Injection Molding International vol. 11 no. 3. This work "Influence of feedstock property estimates and simulations on PIM of PZT" will soon be published as a journal article too.

The understandings from Chapter 2 were then applied in Chapter 3. Chapter 3 follows the same feedstock development approach but with 52 vol. \% PZT powder. In this study, 
simulations using estimated feedstock properties for intricate geometry of microarray was successfully validated using experiments. An extensive study on simulations was also conducted in this chapter to understand possible defects in PIM experiments. Research presented in Chapter 3 is under preparation for submission in "MIM2018: International Conference on Injection Molding of Metals, Ceramics and Carbides" and journal article.

Appendix B and $\mathbf{C}$ reports the study of effect of change in gate location and micro pillar spacing with 3 different microarray geometry. Appendix D repots the raw rheology data for powder-polymer composites. 


\section{CHAPTER 2}

\section{INFLUENCE OF FEEDSTOCK PROPERTY ESTIMATES AND MEASUREMENTS ON POWDER INJECTION MOLDING OF LEAD}

ZIRCONATE TITANATE (PZT)

\subsection{INTRODUCTION}

Piezoelectric ceramics for transducer applications such as actuators, sensors, capacitors, resonators, and high-power transducers have been widely studied $[13,14]$. In order to optimize physical and electromechanical properties of transducer, piezoelectric/polymer composite that consists of active piezoelectric ceramic and passive polymer matrix has been developed [15-18]. Among various piezoelectric ceramic materials, PZT has very high piezoelectric and dielectric properties and is widely used for transducer applications [19]. Various fabrication methods were developed to fabricate piezoelectric/polymer composites such as laser ablation, casting, embossing, micro-pressing, injection molding and fused deposition method. Among these powder injection molding (PIM) is a wellknown for high production rate and complex geometries. Even though, there is previous work on PIM of piezoelectric ceramics, the features sizes are higher than hundreds of microns. It is very difficult to produce high aspect ratio fine features of piezoelectric ceramics using PIM. However, injection molding experiments are highly sensitive to 
feedstock properties and processing conditions. Mold flow computer simulation of traditional injection molding is frequently used in the process optimization. In order to perform a reliable simulation, extended input data have to be provided. Rheological, PVT, specific heat, thermal conductivity, and density data (in the solid and in the molten state) are some of the material properties required as input for the simulation. Some of the properties like thermal conductivity of the PIM feedstock are difficult to measure and are rare in the literature. In addition, it is very expensive to measure all the required properties. Some attempts have also been made to estimate the feedstock properties from measured binder properties for injection molding of ceramic powders $[12,20]$.

3D PIM simulation can be used to optimize the injection molding by effectively reducing the design-to-implementation cycle time, identifying key problems before doing the actual fabrication. Among different, mold flow simulation platforms, Moldex3D is a leading CAE product for PIM industry. It can carry out in-depth simulation for widest range of injection molding processes and to optimize product designs and manufacturability [4]. The aim of the current study is to validate the estimated material properties for 3-dimensional mold flow simulations specifically for 45 vol. \% PZT feedstock by comparing with the experimental results. Subsequently, the effects of feedstock properties on the mold filling behavior and defect formation were studied using the Moldex3D simulation platform. The results from the present study will provide a quantitative understanding of the influence of estimated feedstock properties on injection molding process. 


\subsection{EXPERIMENTAL MATERIALS AND METHODS}

Commercially available PZT was used for feedstock preparation. The morphology of the PZT powder was observed by the scanning electron microscopy (SEM Philips XL30S FEG) and is shown in Figure 1. It can be observed that the fine powders with irregular shape and some amount of agglomeration. Table 1 summarizes the size and density values for PZT powder. A multicomponent binder system consisting of paraffin wax, polypropylene, polyethylene-g-maleic anhydride (L DPE-g-MA), and stearic acid (SA) was used in the current study. Binder system composition details and mixing preparations are provided elsewhere [21].

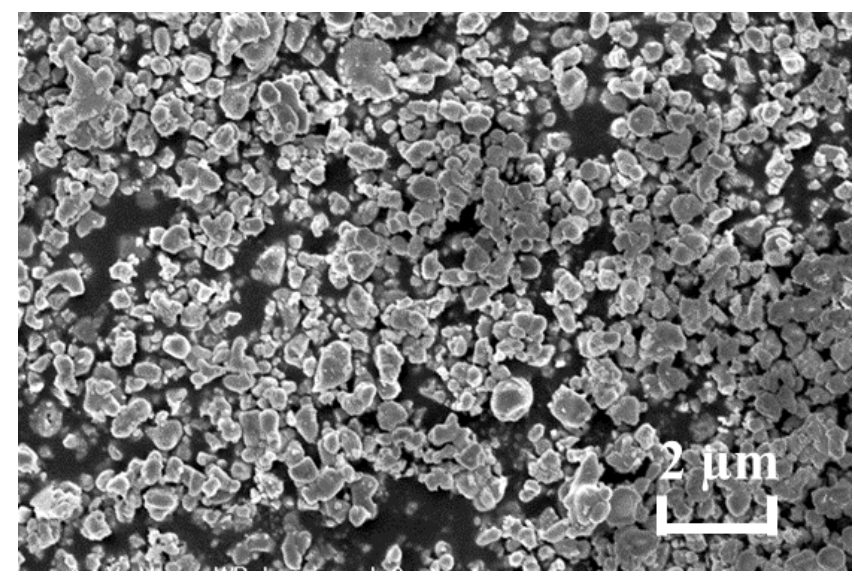

Figure 1: SEM image of PZT powder

Table 1: PZT powder properties

\begin{tabular}{|c|c|c|c|c|c|c|}
\hline \multicolumn{3}{|c|}{ Particle size $(\boldsymbol{\mu m})$} & \multicolumn{3}{c|}{ Density $\left(\mathbf{1 0}^{\mathbf{3}} \mathbf{K g} / \mathbf{m}^{\mathbf{3}}\right)$} & \multirow{2}{*}{$\begin{array}{c}\text { Dielectric } \\
\text { constant }\end{array}$} \\
\cline { 1 - 5 }$\left(\mathrm{D}_{10}\right)$ & $\left(\mathrm{D}_{50}\right)$ & $\left(\mathrm{D}_{90}\right)$ & Apparent & Tap & Pycnometer & \\
\hline 0.31 & 0.52 & 1.01 & 1.62 & 2.54 & 7.98 & 3731 \\
\hline
\end{tabular}

The rheological properties of the binder were measured using a Gottfert Rheograph 2003 capillary rheometer at different shear rates and temperatures. The testing was carried out in accordance with ASTM D3835. The temperatures were between the highest melting 
temperature and the lowest degradation temperature of the binder system. Torque rheometry was performed in the Intelli-Torque Plasticorder (Brabender) in order to determine the maximum packing density of the powder-polymer mixture. The Readco Kurimoto continuous processor with twin shaft is used for continuous extrusion of PZT feedstocks. In this process, two K-Tron T-20 twin screw gravimetric feeders were used for to feed the binder and PZT powder, separately. Injection molding was performed on Sodick Plustech TR 30EH injection molding machine. Thermogravimetric analysis (TGA) was performed on the extruded feedstocks using TA- Q500 (TA instruments) thermal system operated under nitrogen flow in the temperature range of $50-600^{\circ} \mathrm{C}$ with a heating rate of $20{ }^{\circ} \mathrm{C} / \mathrm{min}$ in order to confirm the powder weight fraction in the feedstock. A K-System II Thermal Conductivity System was used to measure the thermal conductivity of the binder. The testing was carried out in accordance with ASTM D5930. Specific heat measurements were carried out on Perkin Elmer DSC7 equipment in accordance with ASTM E1269. The cooling rate was kept constant of $20^{\circ} \mathrm{C} /$ minute. A Gnomix PVT apparatus was used to find the PVT relationships of the feedstock materials. The test was carried out in accordance with ASTM D792. Further experimental details will be described elsewhere [20].

PIM experiments were performed using a Sodick HS30ES micro-injection molding machine. PIM experiments were performed at injection molding conditions of $40 \mathrm{MPa}$ injection pressure, melt temperature of $433 \mathrm{~K}$, mold temperature of $318 \mathrm{~K}$ and injection velocity of $90 \mathrm{~mm} / \mathrm{s}$. Moldex3D software was used to perform PIM simulations for the same process conditions as the PIM experiments. The rectangular plate geometry was designed using Solidworks 2016 software and was imported in the Moldex3D R14.0 software and a runner and sprue system. Moldex3D Mesh Designer software was used to 
generate mesh with 200,000 mesh elements for the rectangular plate and exported to Moldex3D R14.0. Simulations were conducted for 45 vol. \% PZT using estimated material properties. The designed rectangular plate geometry is shown in Figure 2(a) and the meshed plate with runner and sprue are shown in Figure 2(b). Simulations were performed for fill-and-pack conditions.

(a)

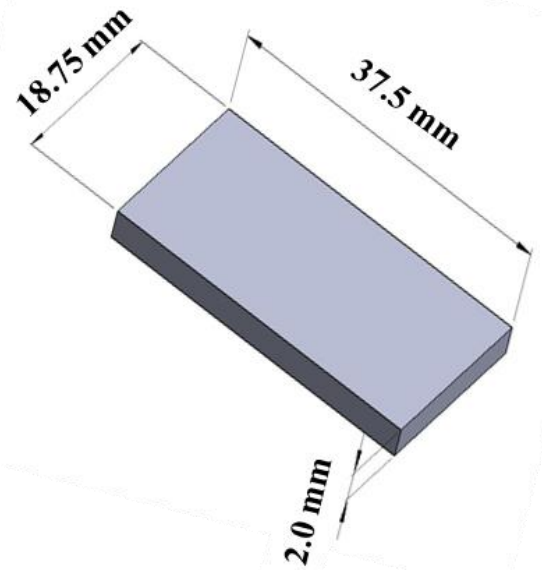

(b)

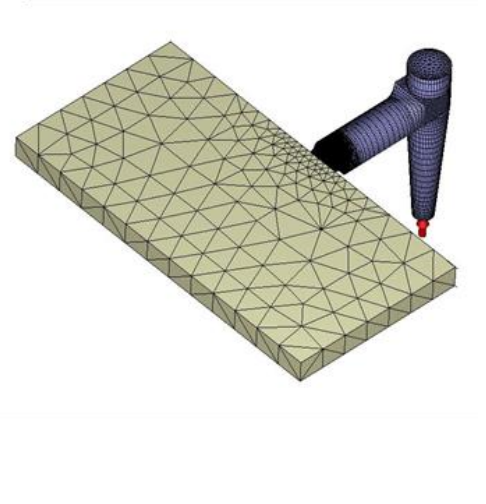

Figure 2: Rectangular plate (a) Solidworks part file (b) Meshed with runner gate system in Moldex3D Designer

\subsection{RESULTS AND DISCUSSION}

\subsubsection{ESTIMATING PROPERTIES OF POWDER-POLYMER MIXTURES}

The experimentally determined binder physical properties were used to estimate properties of PZT powder-polymer mixtures with 45 vol. \% using semi empirical scaling rules that are available to estimate material properties [20,22]. Table 2 to Table 5 summarizes the estimated material properties. In each table, respective measured binder property is listed in bold. Each table contains a footnote with the equations that were used in calculations. Additionally, the viscosity and PVT data required curve fitting to extract constants required for mold filling simulations using Moldex3D software. 
An inverse rule-of-mixtures [22] shown in Equation 3 was used to estimate the melt and solid density of the PZT feedstock. PZT sintered body density was provided by Hayshi Chemical Industry. The mass fractions for powder and binder are 0.88 and 0.12 , respectively that were calculated using Equations1-2. The melt and solid density of 45 vol. \% feedstock is shown in Table 2 .

Table 2: Solid and melt densities of feedstocks with 45 vol. \% PZT powder

\begin{tabular}{|c|c|c|}
\hline Powder vol. \% & $\begin{array}{l}\text { Melt density } \\
\qquad\left(\mathrm{kg} / \mathrm{m}^{3}\right)\end{array}$ & Solid density $\left(\mathrm{kg} / \mathrm{m}^{3}\right)$ \\
\hline O (binder) & 727 & 879 \\
\hline 45 & 3600 & 4020 \\
\hline \multicolumn{3}{|c|}{ 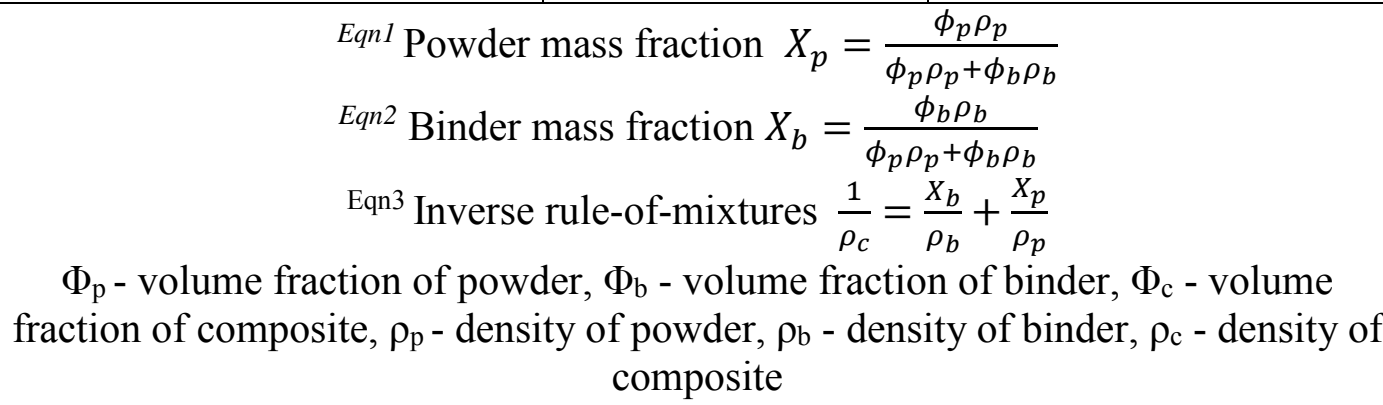 } \\
\hline
\end{tabular}

The specific heat of powder-polymer mixtures has been estimated by different mixing rules [23-27]. In this study, a model that has been successfully applied to mixtures with high volume fraction fillers [24] was used as shown in Equation 4. The parameter, A, is a correction factor assumed to be 0.2 for spherical particles. The specific heat values calculated at various temperatures are shown in Table 3. In this study, a general rule-ofmixtures model [22] was used as represented in Equation 5 to estimate the thermal conductivity. The estimated values of thermal conductivity at various temperatures are shown in Table 3. 
Table 3: Specific heat capacity and thermal conductivity values at various temperatures for feedstocks with 45 vol. \% PZT powder

\begin{tabular}{|c|c|c|}
\hline \multicolumn{3}{|c|}{ Specific heat capacity, $C_{p}(\mathrm{~J} / \mathrm{kg}-\mathrm{K})$} \\
\hline \multirow{2}{*}{ Temperature (K) } & \multicolumn{2}{|c|}{ Powder volume \% } \\
\hline & o (Binder) & 45 \\
\hline 283 & 2077 & 632 \\
\hline 322 & 3360 & 977 \\
\hline 352 & 3840 & 807 \\
\hline 368 & 4894 & 1515 \\
\hline 377 & 4639 & 668 \\
\hline 407 & 3484 & 680 \\
\hline 443 & 2528 & 696 \\
\hline \multicolumn{3}{|c|}{ Thermal conductivity $(\mathrm{W} / \mathrm{m} \cdot \mathrm{K})$} \\
\hline \multirow{2}{*}{ Temperature (K) } & \multicolumn{2}{|c|}{ Powder volume \% } \\
\hline & 0 (Binder) & 45 \\
\hline 315 & 0.2 & 0.46 \\
\hline 336 & 0.2 & 0.45 \\
\hline 356 & 0.2 & 0.45 \\
\hline 377 & 0.2 & 0.44 \\
\hline 397 & 0.2 & 0.43 \\
\hline 417 & 0.2 & 0.42 \\
\hline 436 & 0.2 & 0.42 \\
\hline \multicolumn{3}{|c|}{$\begin{array}{c}{ }^{E q n 4} \text { Specific heat } C_{p_{c}}=\left[C_{p_{b}} X_{b}+C_{p_{p}} X_{p}\right] *\left[1+A * X_{b} X_{p}\right] \\
{ }^{E q n 5} \text { Thermal conductivity } \lambda_{c}=\lambda_{b} \phi_{b}+\lambda_{p} \phi_{p}\end{array}$} \\
\hline
\end{tabular}

The specific volume was calculated using the general rule-of-mixtures as shown in

Equation 6 [22]. Figure 2 shows the comparative plot of specific volumes at 0, 100, and $200 \mathrm{MPa}$ pressure for 45 vol. \% PZT powder. Additionally, to perform mold-filling simulations in Moldex3D software, specific volume of the material needs to be represented in terms of fitted constants. There are multiple parameters $\left(b_{5}, b_{6}, b_{9}, b_{3 m}, b_{4 m}, b_{3 s}\right.$ and $b_{4 s}$, $b_{1 m}, b_{2 m}, b_{1 s}$ and $b_{2 s} b_{7}$ and $\left.b_{8}\right)$ related to specific volume are the required input parameters for Moldex3D simulation software. A Dual-domain Tait Equation (Equation 7, Table 4) was used to extract these fitted constants using curve fitting for $0,50,100,150,200 \mathrm{MPa}$ pressure for 45 vol. \% PZT powder. The values of these coefficients are summarized in Table 4. 


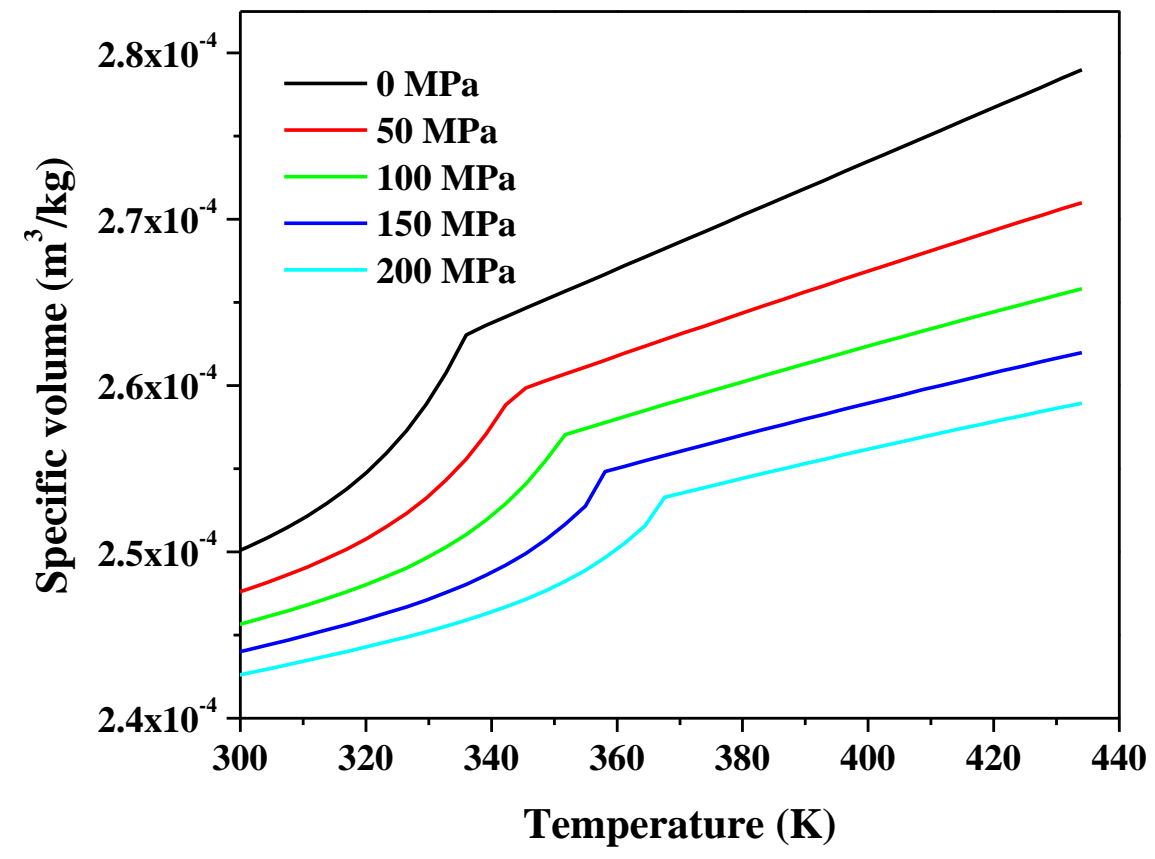

Figure 3: PVT behavior for 0, 100, and 200 MPa pressures for 45 vol. \% PZT powder.

Table 4: Dual-domain Tait constants for feedstocks with 45 vol. \% PZT powder

\begin{tabular}{|c|c|c|}
\hline \multirow{2}{*}{$\begin{array}{l}\text { dual-domain Tait } \\
\text { constants }\end{array}$} & \multicolumn{2}{|c|}{ Powder volume \% } \\
\hline & o (Binder) & 45 \\
\hline$b_{5, K}$ & 336 & 336 \\
\hline$b_{6}, K / P a$ & $1.5 \times 10^{-7}$ & $1.54 \times 10^{-7}$ \\
\hline$b_{1 m}, m^{3} / k g$ & $1.3 \times 10^{-3}$ & $2.63 \times 10^{-4}$ \\
\hline$b_{2 m}, \mathrm{~m}^{3} / \mathrm{kg} \cdot \mathrm{K}$ & $1.3 \times 10^{-6}$ & $1.13 \times 10^{-7}$ \\
\hline$b_{3 m}, P a$ & $1.3 \times 10^{8}$ & $2.24 \times 10^{8}$ \\
\hline$b_{4 m}, K^{-1}$ & $6.0 \times 10^{-3}$ & $3.04 \times 10^{-4}$ \\
\hline$b_{1 s}, m^{3} / \mathrm{kg}$ & $1.2 \times 10^{-3}$ & $2.52 \times 10^{-4}$ \\
\hline$b_{2 s}, \mathrm{~m}^{3} / \mathrm{kg} \cdot \mathrm{K}$ & $8.6 \times 10^{-7}$ & $1.24 \times 10^{-7}$ \\
\hline$b_{3 s}, P a$ & $2.4 \times 10^{8}$ & $5.08 \times 10^{8}$ \\
\hline$b_{4 s}, K^{-1}$ & $4.2 \times 10^{-3}$ & $1.46 \times 10^{-3}$ \\
\hline$b_{7}, m^{3} / k g$ & $8.5 \times 10^{-5}$ & $1.20 \times 10^{-5}$ \\
\hline$b_{8}, K^{-1}$ & $6.7 \times 10^{-2}$ & $9.40 \times 10^{-2}$ \\
\hline$b_{9,} P^{-1}$ & $1.4 \times 10^{-8}$ & $2.05 \times 10^{-8}$ \\
\hline
\end{tabular}




$$
\begin{gathered}
{ }^{E q n 6} \text { Specific volume } v_{c}=X_{p} v_{p}+v_{b}\left(1-X_{f}\right) \\
{ }^{E q n 7} v(T, p)=v_{o}(T)\left[1-C \ln \left(1+\frac{p}{B(T)}\right)+v_{t}(T, p)\right] \\
T>T_{t}: \quad v_{o}=b_{1 m}+b_{2 m}\left(T-b_{5}\right), \\
B(T)=b_{3 m} e^{\left[-b_{4 m}\left(T-b_{5}\right)\right]}, \\
v_{t}(T, p)=0 \\
v_{o}=b_{1 s}+b_{2 s}\left(T-b_{5}\right), \\
B(T)=b_{3 s} e^{\left[-b_{4 s}\left(T-b_{5}\right]\right.}, \\
v_{t}(T, p)=b_{7} e^{\left[b_{8}\left(T-b_{5}\right)-\left(b_{9} p\right)\right]}
\end{gathered}
$$

$v(T, p)$ - specific volume at a given temperature and pressure $v_{o}$ - specific volume at zero-gauge pressure, $p$ - pressure, $C$ - constant, 0.0894

$b_{1 s}, b_{2 s}, b_{3 s}, b_{4 s}, b_{5}, b_{7}, b_{8}, b_{9}$ - curve-fitted coefficients $b_{1 m}, b_{2 m}, b_{3 m}, b_{4 m}, b_{5}, b_{6}$ - curve-fitted coefficients

A simplified Krieger-Dougherty [28] viscosity model was used to estimate the viscosity values (Equation 8, Table 5). The Cross-WLF model [29] was used to model the viscosity dependence of the powder-polymer mixture on shear rate (Equation 9, Table 5). The temperature dependence of viscosity of PZT powder-polymer mixture [29] was estimated using Equation 10. The values of the coefficients $\left(T^{*}, D_{1}\right.$ and $\left.A_{1},\right)$ were extracted by curve-fitting the estimated viscosity for 45 vol. \% PZT powder at various shear rates and temperatures. Figure 3 shows the shear-rate dependence of viscosity for feedstocks with 45 vol. \% PZT powder at 413, 420, 426 and $433 \mathrm{~K}$. The zero-shear viscosity was estimated from the plateau region at low shear rate while the power law index was obtained from the slope at higher shear rates. The curve-fitted WLF parameters $n, \tau^{*}, D_{1}, T^{*}, A_{1}$ and $A_{2}$ were estimated for four different temperatures $(413,420,426$ and $433 \mathrm{~K})$. The estimated 
for $\mathrm{n}$ and $\tau^{*}$ for each temperature were then averaged. All the coefficients related to viscosity are summarized in Table 5.

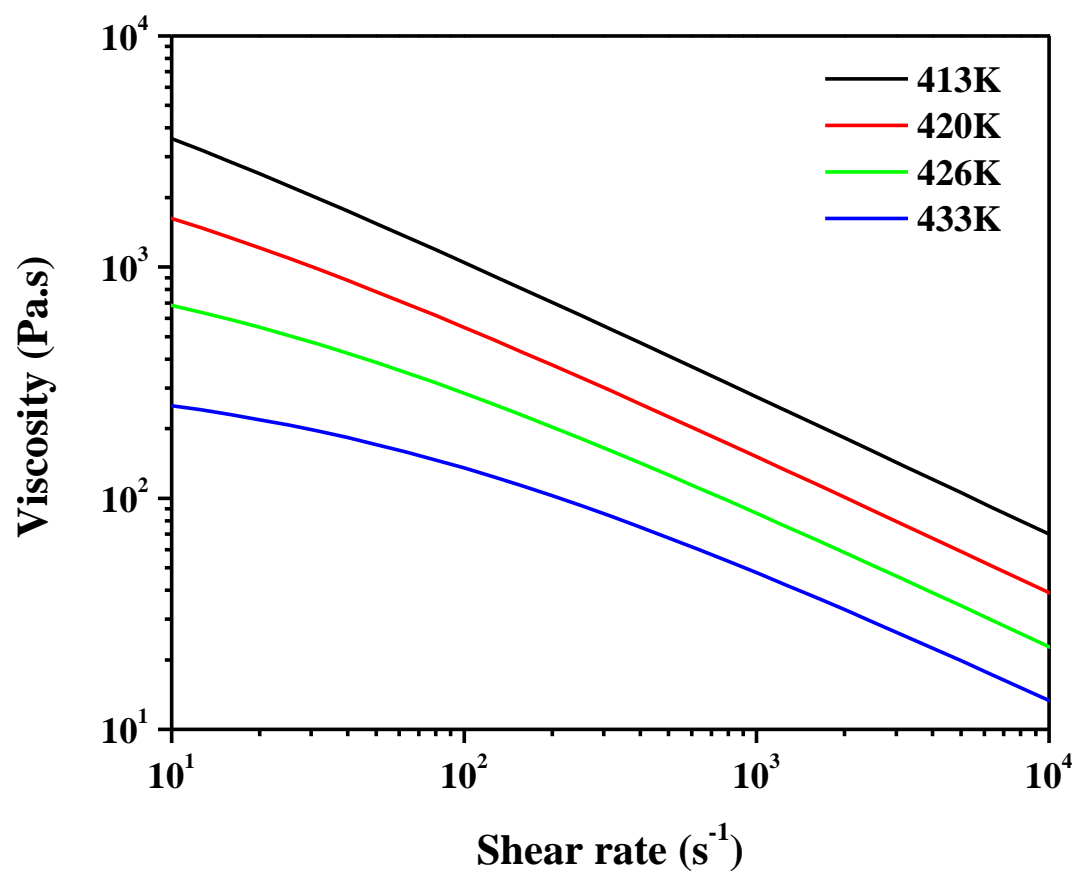

Figure 4: Comparison of viscosity with shear rate at different temperatures for 45 vol. \% PZT powder.

Table 5: Cross-WLF constants for feedstocks with 45 vol. \% PZT powder

\begin{tabular}{|c|c|c|}
\hline \multirow{2}{*}{$\begin{array}{c}\text { Cross-WLF } \\
\text { constants }\end{array}$} & \multicolumn{2}{|c|}{ Powder volume \% } \\
\cline { 2 - 3 } & $\mathbf{0}$ (Binder) & 45 \\
\hline$n$ & $\mathbf{0 . 4 0}$ & 0.40 \\
\hline$\tau^{*}, P a$ & $\mathbf{7 9 3}$ & 15831 \\
\hline$D_{l}, P a \cdot s$ & $\mathbf{4 . 2 9} \times \mathbf{1 0}^{\mathbf{2 3}}$ & $1.08 \times 10^{16}$ \\
\hline$T^{*}, K$ & $\mathbf{3 3 3 . 0 0}$ & 367.87 \\
\hline$A_{l}$ & $\mathbf{7 8 . 1 3}$ & 56.59 \\
\hline$A_{2}, K$ & $\mathbf{5 1 . 6 0}$ & 51.60 \\
\hline \multicolumn{2}{|c|}{$E q n 8$ Viscosity of composite } & $\eta_{c}=\frac{\eta_{\mathrm{b}}}{\left[1-\frac{\phi_{\mathrm{p}}}{\phi_{\max }}\right]^{2}}$ \\
\hline
\end{tabular}




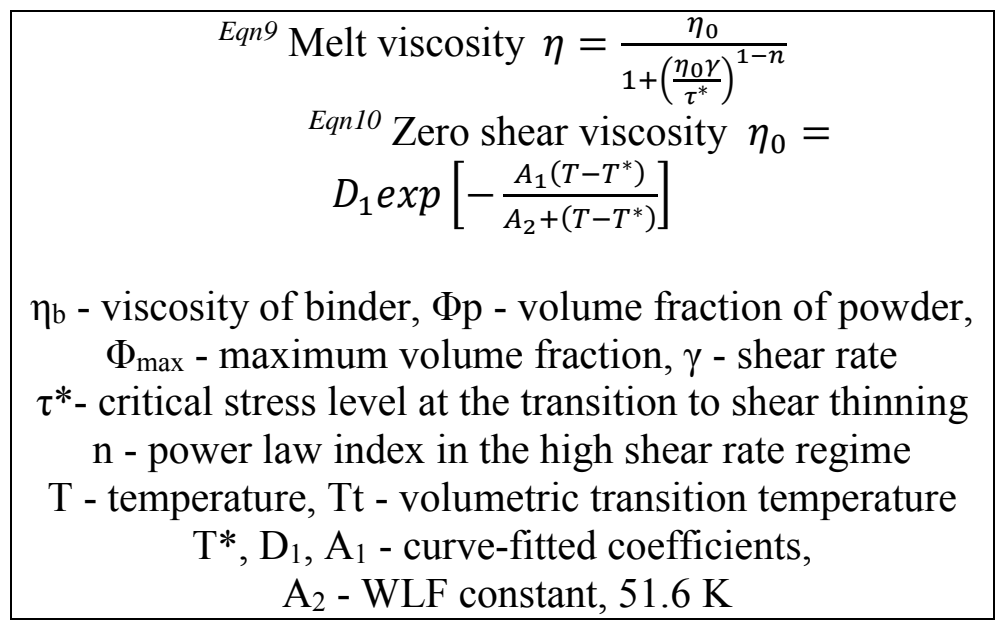

\subsubsection{EXPERIMENTAL AND SIMULATIONS RESULTS}

The cavity dimensions and process conditions from the experiments were used to perform simulations. Simulations were carried out with estimate and hybrid feedstock properties as mentioned in the table, at different injection velocities and pressure to predict incomplete to complete mold filling behavior of 45 vol. \% PZT feedstock. PIM base plates using different injection velocities are shown in Figure 5. At injection velocity of $90 \mathrm{~mm} / \mathrm{s}$ and packing pressure of $400 \mathrm{~kg} / \mathrm{cm}^{2}$, a completely filled mold cavity was achieved. The PIM of completely filled $0.45 \%$ PZT base plate samples have an average cavity weight of 5.66 g. From Moldex3D simulations the completely filled mold cavity weight is $5.25 \mathrm{gm}$ with estimated properties and $5.43 \mathrm{gm}$ with hybrid properties. The error in estimating cavity weight with respect to experiments around 5 to $7 \%$ using estimated and hybrid properties. 
Table 6: Data set used for simulations

\begin{tabular}{|c|c|c|}
\hline \multirow{2}{*}{ Material parameters } & \multicolumn{2}{|c|}{ Feedstock properties } \\
\cline { 2 - 3 } & Estimated & Hybrid \\
\hline Density & Estimated density & Estimated density \\
\hline Specific heat & Estimated specific heat & Estimated specific heat \\
\hline $\begin{array}{c}\text { Thermal } \\
\text { conductivity }\end{array}$ & $\begin{array}{c}\text { Estimated thermal } \\
\text { conductivity }\end{array}$ & $\begin{array}{c}\text { Estimated thermal } \\
\text { conductivity }\end{array}$ \\
\hline Viscosity & Estimated viscosity & Experimental viscosity \\
\hline Specific Volume & Estimated specific volume & Estimated specific volume \\
\hline
\end{tabular}

Table 6 represent the data set used in Moldex3D simulations. To simulate accurate mold filling behavior, viscosity of developed feedstock was measured and used to replace estimated viscosity in hybrid feedstock properties

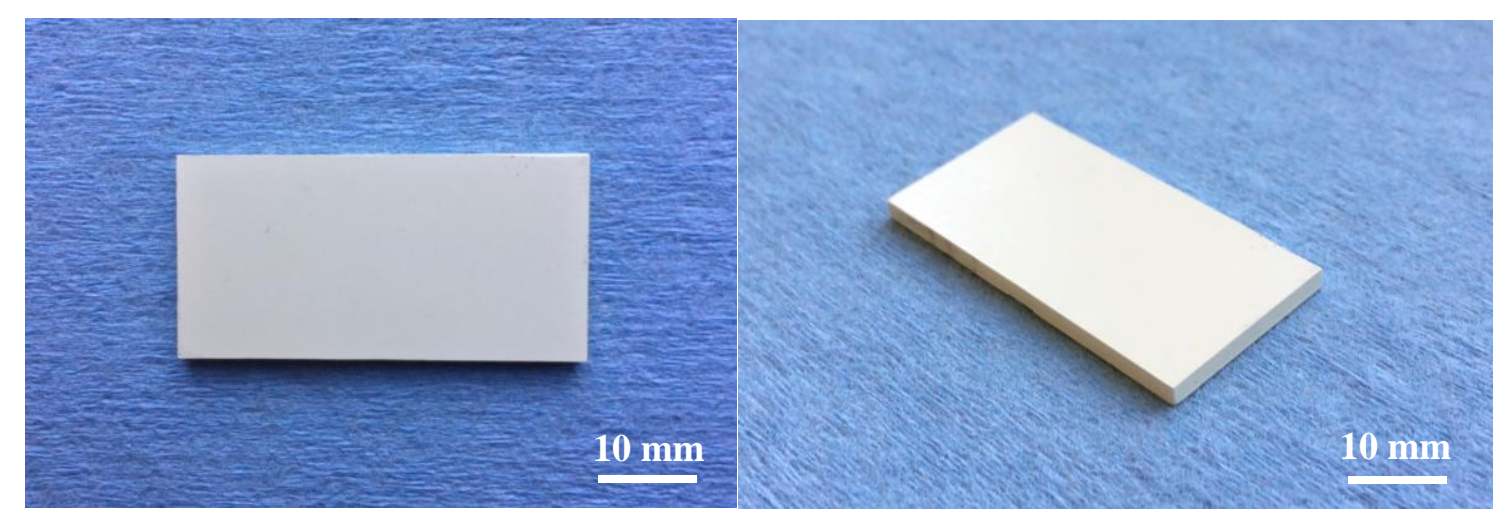

Figure 5: PIM experiment for 45 vol. \% PZT rectangular plate with $100 \%$ filling at injection velocity $90 \mathrm{~mm} / \mathrm{s}$ and injection pressure at $40 \mathrm{MPa}$ (a) top view (b) $3 \mathrm{D}$ perspective view 


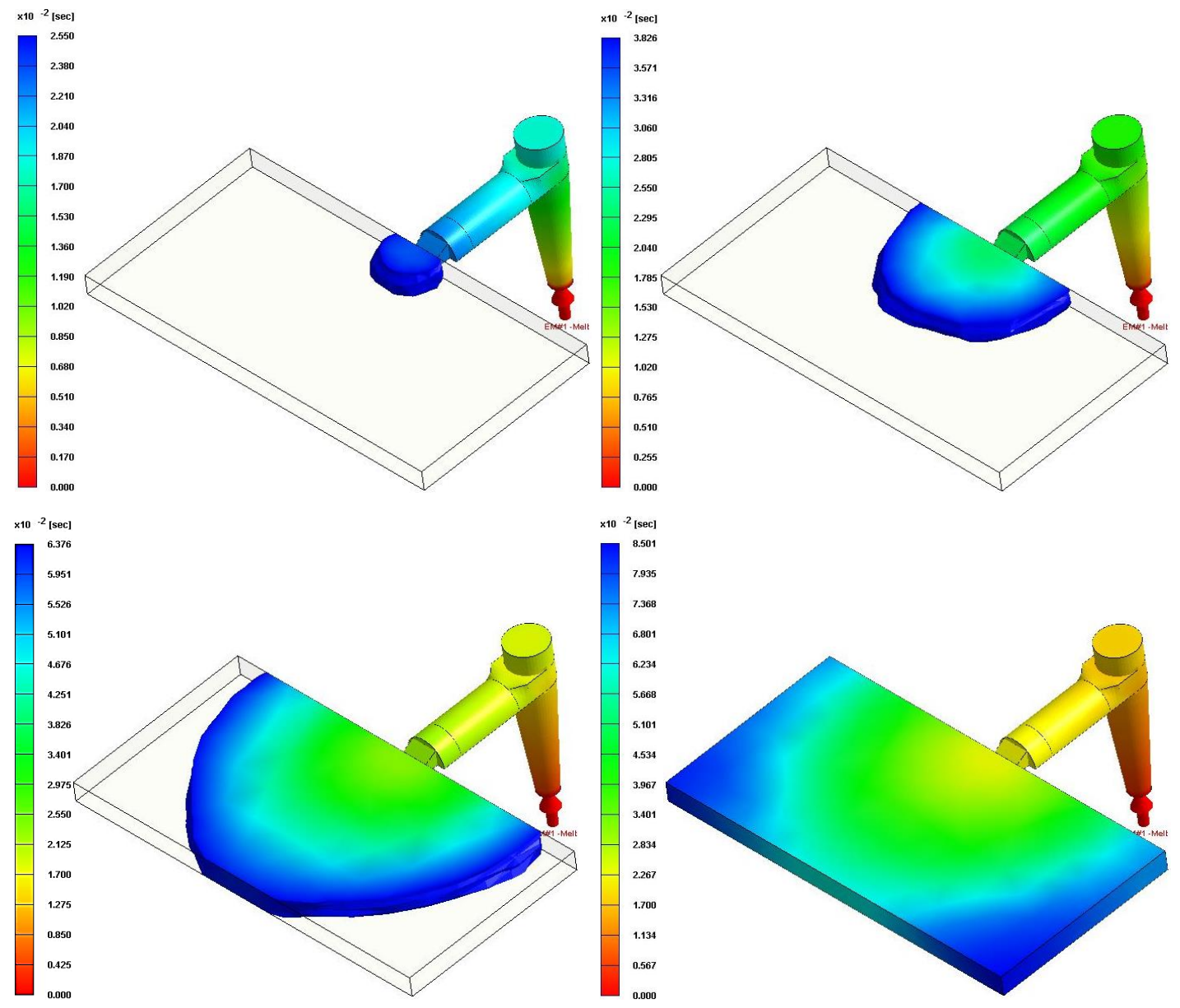

Figure 6: Moldex3D simulation for $0.45 \%$ PZT base plate - $100 \%$ filled at injection velocity $90 \mathrm{~mm} / \mathrm{s}$ : (a) $30 \%$ filled in $0.025 \mathrm{~s}$, (b) $45 \%$ filled in $0.038 \mathrm{~s}$, (c) $75 \%$ filled in $0.064 \mathrm{~s}$ and $(\mathrm{d}) 100 \%$ filled in $0.085 \mathrm{~s}$ 


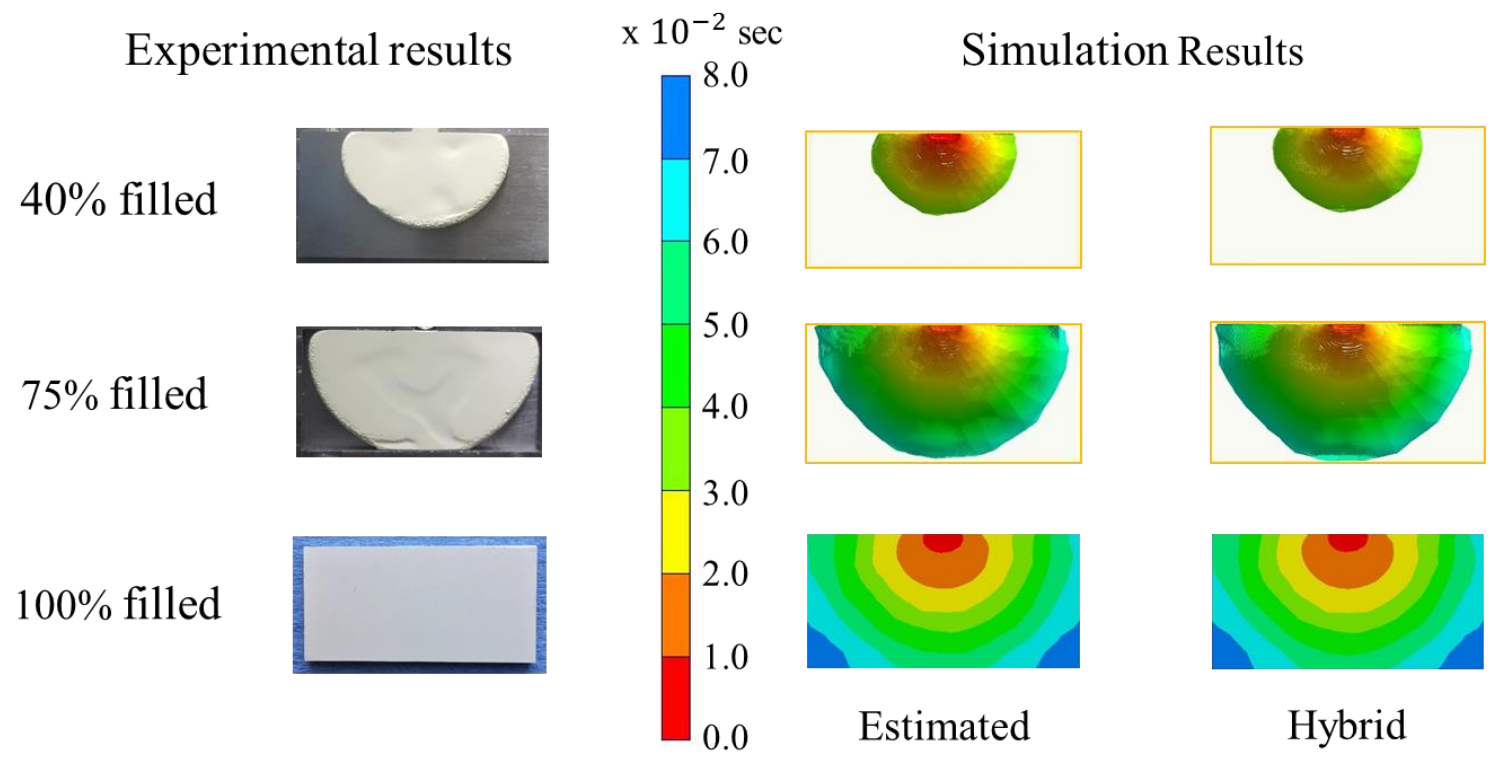

Figure 7: Evolution of simulated flow front for $0.45 \%$ PZT base plate compared with experimental results

Figure 6 shows a progressive injection molding behavior inside the rectangular geometry and are comparable to one observed in PIM experiments. Injection molding behavior in a flat plate is further studied in figure 7; it is observed that simulations exactly predict the evolution of mold filling behavior at $40 \%, 75 \%$ and $100 \%$. As seen in experiments, it is expected that the filling flow-front will hit the wall and spread in rest of the cavity. This phenomenon is evidently seen in simulations with hybrid material properties.
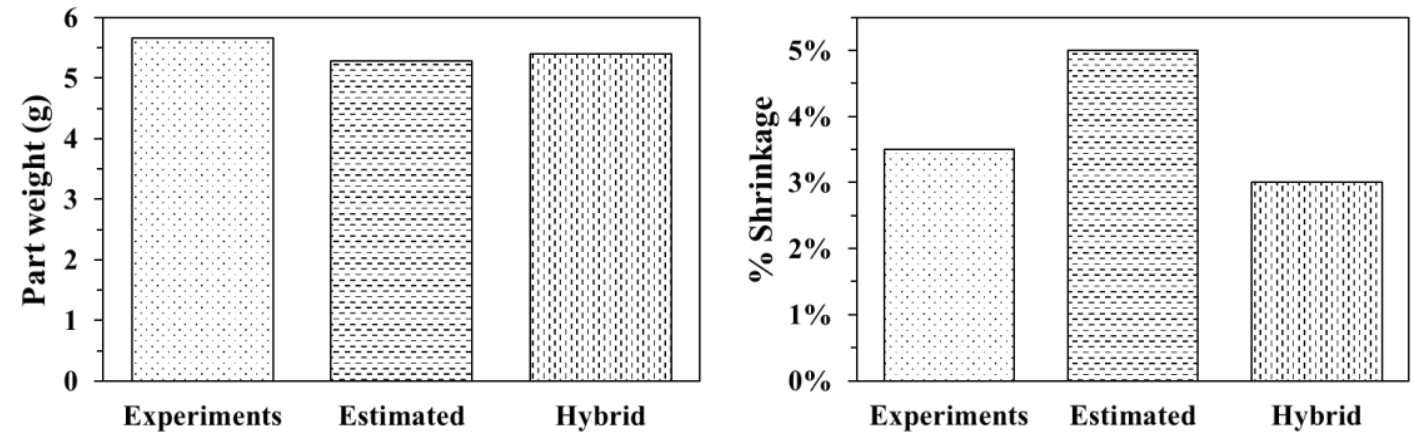

Figure 8: Experiments compared with simulations using estimated and hybrid material properties - (a) Part weight of base plate (b) Volumetric shrinkage (\%) of base plate 
Table 7: Statistical comparison of experiments compared with simulations using estimated and hybrid material properties (a) relative error in part weight of simulations w.r.t. experiments (b) Volumetric shrinkage (\%) of base plate

\begin{tabular}{|c|c|c|}
\hline \multirow{2}{*}{$\begin{array}{c}\text { Cavity Part weight } \\
\% \text { error }\end{array}$} & Estimated & Hybrid \\
\cline { 2 - 3 } & $7 \%$ & $5 \%$ \\
\hline
\end{tabular}

\begin{tabular}{|l|c|c|c|}
\hline \multirow{2}{*}{ Volumetric shrinkage (\%) } & Experiments & Estimated & Hybrid \\
\cline { 2 - 4 } & $3.5 \%$ & $5 \%$ & $3 \%$ \\
\hline
\end{tabular}

The average volumetric shrinkage for PIM experiment is $3.5 \%$ and is $5 \%$ and $3 \%$ with Moldex3D simulations.

\subsection{SUMMARY}

PZT feedstock for 45 vol. \% solids loading was successfully formulated and injection molding experiments were performed to get completely molded parts. To perform PIM simulations, physical, thermal, rheological properties and PVT parameters were estimated for 45 vol. \% PZT feedstock. Estimated PIM material properties were used as input parameters and PIM simulations were performed using same process conditions as that of PIM experiments process conditions. PIM simulations results indicate that injection molding behavior predicted with PIM simulations is comparable to the molding behavior with experiments. Completely filled base plate weights from PIM experiments and simulation using estimated and hybrid properties were $5.66 \mathrm{gm}, 5.25 \mathrm{gm}$ and $5.43 \mathrm{gm}$ respectively. Additionally, volumetric shrinkage predictions with PIM simulations using estimated materials properties (5\%) and hybrid material properties $(3 \%)$ are comparable to PIM experiments (3.5\%). Using hybrid material properties to perform PIM simulations can help reduce the number of trial-and-error experiments involved in designing new PIM 
feedstocks and PIM process parameters. Furthermore, such an approach can be utilized in selecting component geometry attributes to optimize PIM process. 


\section{CHAPTER 3}

\section{INFLUENCE OF FEEDSTOCK PROPERTY ESTIMATES AND SIMULATIONS}

ON POWDER INJECTION MOLDING OF LEAD ZIRCONATE TITANATE (PZT) MICROARRAYS

\subsection{INTRODUCTION}

Lead zirconate titanate (PZT) is most widely and extensive used piezoelectric ceramic. It is used as sensor and actuator for ultrasound probes and various other applications. Commercially, PZT is fabricated using micro maching technique such as dice and fill. a block of fired PZT is micro machined with a series of parallel and perpendicular cuts to form the microarrays[11]. The size of micro pillars is dependent on the accuracy of dicing saw and ability of ceramic to withstand the process. The dicing process itself is time consuming. Powder injection molding(PIM), especially ceramic injection molding (CIM) is relatively faster alternative than this commercially used technique. With CIM, a variety of rod size, shape and spacing can also be obtained [7]. Any PIM technique consist of the following steps, feedstock formulation, injection molding, debinding and sintering. Feedstock formulation is very important, as it cannot be corrected in any of the subsequent step. If feedstock formulation for a given geometry is not suitable to PIM, then trial and error technique should be performed to get $100 \%$ filled and packed part. In current work, 
simulations are performed to study the mold filling behavior of 52 vol. \% PZT feedstock with a 3D geometry with micropillar arrays. These simulations are compared to experimental results. In order to perform these simulations, feedstock properties such as viscosity, specific volume, thermal conductivity and specific heat was estimated using semi empirical formulae. A detailed study was also performed on possible defects in PIM of PZT, to avoid any other trial and error in the process.

\subsection{EXPERIMENTAL MATERIALS AND METHODS}

Commercially available lead zirconate titanate (PZT) powder and a wax-polymer binder was used in feedstock development. The binder is composed of paraffin wax, microcrystalline wax, carnauba wax, polypropylene, polyethylene and stearic acid. Maximum solids was determined for PZT polymer composite using torque rheometry which was performed in the Intelli-Torque Plasticorder (Barbender). Feedstock for 52vol\% PZT content was developed. Injection molding was performed on Sodick TR30EH injection molding machine. The CAD model was designed in SolidWorks according to the experimental setup. The overall length is $37.50 \mathrm{~mm}$, width $18.75 \mathrm{~mm}$ and thickness of 2 $\mathrm{mm}$. The microarray is designed in $3 \times 3$ configuration with each micro-pillar has length (l) of $1 \mathrm{~mm}$ and diameter $(d)$ of $0.19 \mathrm{~mm}$. The aspect ratio $(l / d)$ is 5.263 . 

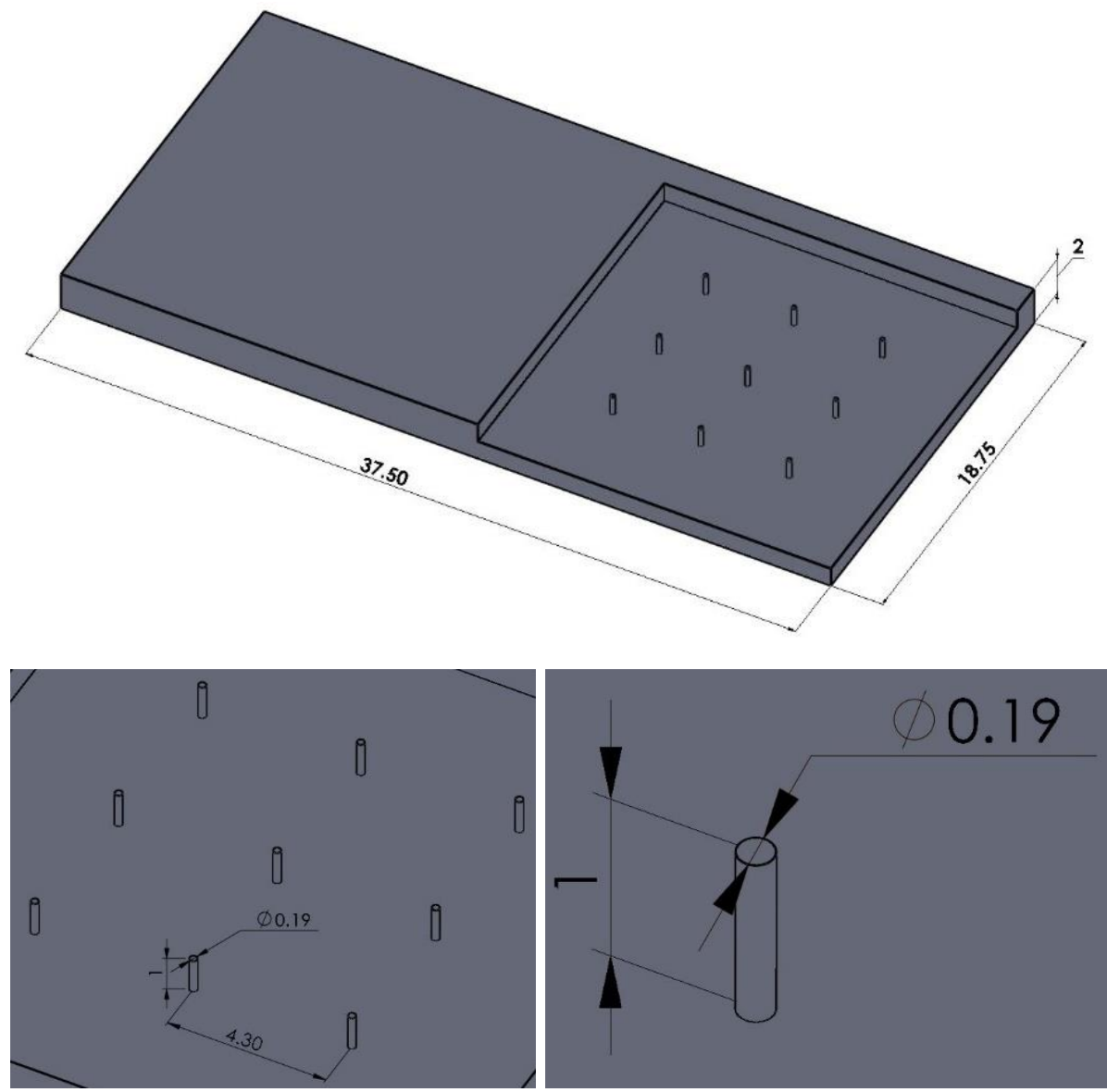

Figure 9: Microarray geometry: SolidWorks part file

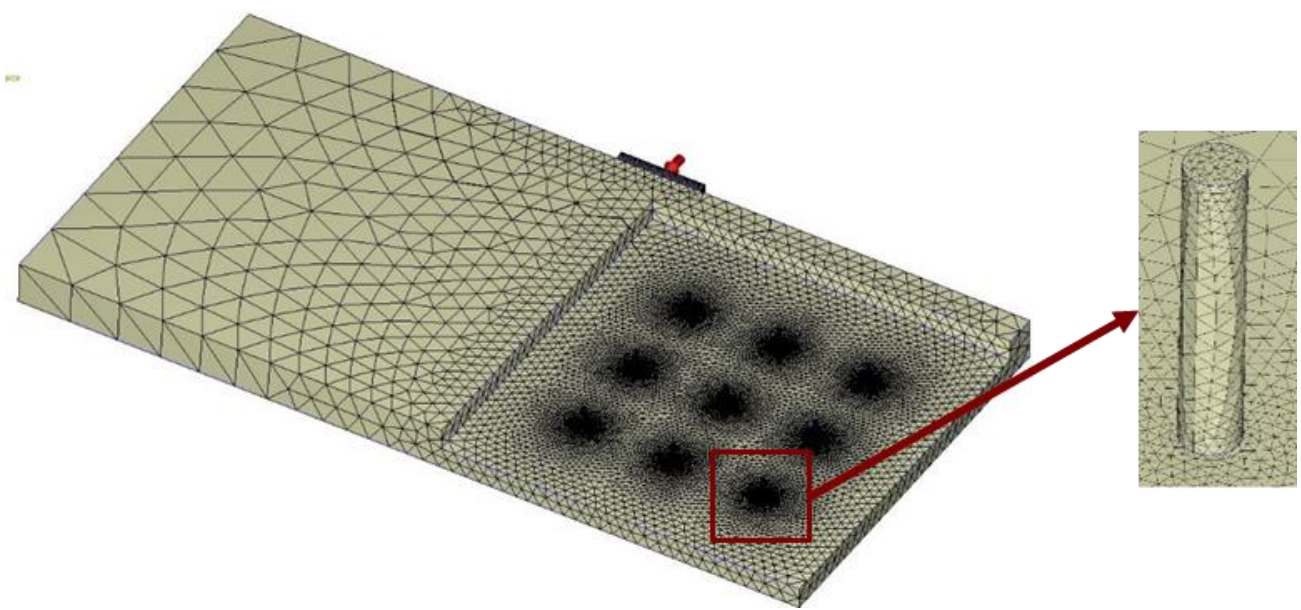

Figure 10: Meshed in Moldex3D designer 
The CAD model was then imported in Moldex3D designer as .step file. The model is meshed into 367,868 elements and has mesh volume of 1.11 cc. The PIM process parameters are as shown in table 1. These values were used for PIM experiments and simulations.

Table 8: Process conditions for powder injection molding

\begin{tabular}{cc}
\hline Process parameter & Values \\
\hline Mold temperature & $60^{\circ} \mathrm{C}$ \\
Melt temperature & $160^{\circ} \mathrm{C}$ \\
Ram position & $25 \mathrm{~mm}$ \\
Injection velocity & $120 \mathrm{~mm} / \mathrm{s}$ \\
Packing pressure & $40 \mathrm{MPa}$ \\
\hline
\end{tabular}

Material properties such as specific heat, thermal conductivity, specific volume and viscosity were estimated using semi-empirical formulas and feedstock models. Using these values a material database file for $52 \mathrm{vol} \%$ PZT was compiled in Moldex3D software. This material file along with process conditions was used for performing simulations.

\subsection{RESULTS AND DISCUSSION}

\subsubsection{ESTIMATING MATERIAL PROPERTY}

Material properties are estimated for 52 vol. \% PZT polymer composite using previous determined binder physical properties. Table 10 to Table 12 summarizes these estimated properties. Density was estimated as a function of mass fraction. Powder mass fraction was calculated using Equation (3.10)

$$
X_{p}=\frac{\phi_{p} \rho_{p}}{\phi_{p} \rho_{p}+\phi_{b} \rho_{b}}
$$


Binder mass fraction was calculated using Equation (3.2)

$$
X_{b}=\frac{\phi_{b} \rho_{b}}{\phi_{p} \rho_{p}+\phi_{b} \rho_{b}}
$$

Density of powder and binder was measured, and density of composite was estimated with the help of inverse rule of mixtures Equation (3.3).

$$
\frac{1}{\rho_{c}}=\frac{X_{b}}{\rho_{b}}+\frac{X_{p}}{\rho_{p}}
$$

Table 9: Solid and melt densities of feedstock with 52 vol. \% PZT powder

\begin{tabular}{ccc}
\hline Powder volume $\%$ & Melt density $\left(\mathrm{kg} / \mathrm{m}^{3}\right)$ & Solid density $\left(\mathrm{kg} / \mathrm{m}^{3}\right)$ \\
\hline 0 (binder) & $\mathbf{7 2 7}$ & $\mathbf{8 7 9}$ \\
$\mathbf{5 2}$ & 4090 & 4500 \\
\hline
\end{tabular}

Specific heat and thermal conductivity were estimated as a function of temperature. The specific heat of PZT powder-polymer composite (Equation (3.4)) was estimated using specific heat and mass fraction of individual PZT and binder

$$
C_{p_{c}}=\left[C_{p_{b}} X_{b}+C_{p_{p}} X_{p}\right] *\left[1+A * X_{b} X_{p}\right]
$$

The specific heat for 52 vol. \% PZT polymer composite for a range of temperature from $283 \mathrm{~K}$ to $443 \mathrm{~K}$ is as shown in Table 10. The thermal conductivity of the composite (Equation (3.5)) was estimated using thermal conductivity and volume fraction of PZT powder and binder

$$
\lambda_{c}=\lambda_{b} \phi_{b}+\lambda_{p} \phi_{p}
$$


Table 10: Specific heat capacity and thermal conductivity values at various temperatures for feedstock with 52 vol. \% PZT powder

\begin{tabular}{ccc}
\hline \multicolumn{3}{c}{ Specific heat capacity, $\boldsymbol{C}_{\boldsymbol{p}}(\mathbf{J} / \mathbf{k g}-\mathbf{K})$} \\
\hline \multicolumn{3}{c}{ Powder vol \% } \\
\cline { 2 - 3 } Temperature $(\mathrm{K})$ & $\mathbf{0}($ Binder $)$ & $\mathbf{5 2}$ \\
\hline $\mathbf{2 8 3}$ & $\mathbf{2 0 7 7}$ & 585 \\
\hline $\mathbf{3 2 2}$ & $\mathbf{3 3 6 0}$ & 853 \\
\hline $\mathbf{3 5 2}$ & $\mathbf{3 8 4 0}$ & 721 \\
\hline $\mathbf{3 6 8}$ & $\mathbf{4 8 9 4}$ & 1272 \\
\hline $\mathbf{3 7 7}$ & $\mathbf{4 6 3 9}$ & 613 \\
\hline $\mathbf{4 0 7}$ & $\mathbf{3 4 8 4}$ & 623 \\
\hline $\mathbf{4 4 3}$ & $\mathbf{2 5 2 8}$ & 635 \\
\hline
\end{tabular}

Thermal conductivity $(\mathrm{W} / \mathrm{m} \cdot \mathrm{K})$

\begin{tabular}{ccc}
\hline \multirow{2}{*}{ Temperature $(\mathrm{K})$} & \multicolumn{3}{c}{ Powder vol \% } \\
\cline { 2 - 3 } & $\mathbf{0}$ (Binder) & $\mathbf{5 2}$ \\
\hline $\mathbf{3 1 5}$ & $\mathbf{0 . 2}$ & 0.53 \\
\hline $\mathbf{3 3 6}$ & $\mathbf{0 . 2}$ & 0.52 \\
\hline $\mathbf{3 5 6}$ & $\mathbf{0 . 2}$ & 0.51 \\
\hline $\mathbf{3 7 7}$ & $\mathbf{0 . 2}$ & 0.50 \\
\hline $\mathbf{3 9 7}$ & $\mathbf{0 . 2}$ & 0.49 \\
\hline $\mathbf{4 1 7}$ & $\mathbf{0 . 2}$ & 0.49 \\
\hline $\mathbf{4 3 6}$ & $\mathbf{0 . 2}$ & 0.48 \\
\hline
\end{tabular}

Specific volume was estimated as a function of temperature and pressure. Using rule of mixtures (Equation (3.6)) specific volume for 52 vol\% PZT feedstock was estimated from pressure 0 to $200 \mathrm{MPa}$ and temperature $10-300^{\circ} \mathrm{C}$.

$$
v_{c}=X_{p} v_{p}+v_{b}\left(1-X_{f}\right)
$$

Dual-domain Tait model (Equation (3.7)) was used to extract constant from curve fitting of specific volume as shown in Table 11.

$$
v(T, p)=v_{o}(T)\left[1-C \ln \left(1+\frac{p}{B(T)}\right)+v_{t}(T, p)\right]
$$

For $T>T_{t}$,

$$
v_{o}=b_{1 m}+b_{2 m}\left(T-b_{5}\right)
$$




$$
\begin{gathered}
B(T)=b_{3 m} e^{\left[-b_{4 m}\left(T-b_{5}\right)\right]} \\
v_{t}(T, p)=0
\end{gathered}
$$

For $T<T_{t}$,

$$
\begin{gathered}
v_{o}=b_{1 s}+b_{2 s}\left(T-b_{5}\right), \\
B(T)=b_{3 s} e^{\left[-b_{4 s}\left(T-b_{5}\right]\right.}, \\
v_{t}(T, p)=b_{7} e^{\left[b_{8}\left(T-b_{5}\right)-\left(b_{9} p\right)\right]}
\end{gathered}
$$

\begin{tabular}{|c|c|c|}
\hline \multirow{2}{*}{$\begin{array}{l}\text { Dual-domain Tait } \\
\text { constants }\end{array}$} & \multicolumn{2}{|c|}{ Powder vol \% } \\
\hline & O (Binder) & 52 \\
\hline$b_{5}, K$ & 336 & 335 \\
\hline$b_{6}, K / P a$ & $1.5 \times 10^{-7}$ & $1.17 \times 10^{-7}$ \\
\hline$b_{1 m}, m^{3} / k g$ & $1.3 \times 10^{-3}$ & $2.3 \times 10^{-4}$ \\
\hline$b_{2 m}, m^{3} / \mathrm{kg} \cdot K$ & $1.3 \times 10^{-6}$ & $1.26 \times 10^{-7}$ \\
\hline$b_{3 m}, P a$ & $1.3 \times 10^{8}$ & $7.34 \times 10^{8}$ \\
\hline$b_{4 m}, K^{-1}$ & $6.0 \times 10^{-3}$ & $5.0 \times 10^{-4}$ \\
\hline$b_{1 s}, m^{3} / k g$ & $1.2 \times 10^{-3}$ & $2.28 \times 10^{-4}$ \\
\hline$b_{2 s}, m^{3} / \mathrm{kg} \cdot K$ & $8.6 \times 10^{-7}$ & $1.45 \times 10^{-7}$ \\
\hline$b_{3 s}, P a$ & $2.4 \times 10^{8}$ & $2.37 \times 10^{8}$ \\
\hline$b_{4 s}, K^{-1}$ & $4.2 \times 10^{-3}$ & $1.9 \times 10^{-3}$ \\
\hline$b_{7}, m^{3} / k g$ & $8.5 \times 10^{-5}$ & $5 \times 10^{-6}$ \\
\hline$b_{8}, K^{-1}$ & $6.7 \times 10^{-2}$ & $1.8 \times 10^{-1}$ \\
\hline$b_{9,} P a^{-1}$ & $1.4 \times 10^{-8}$ & $2 \times 10^{-8}$ \\
\hline
\end{tabular}

Table 11: Dual-domain Tait constants for binder and 52vol\% PZT feedstock

Viscosity was estimated as a function of temperature and shear rate. Viscosity of composite was estimated using simplified Krieger Dougherty model as shown in Equation (3.8) [30].

$$
\eta_{c}=\frac{\eta_{\mathrm{b}}}{\left[1-\frac{\phi_{\mathrm{p}}}{\phi_{\max }}\right]^{2}}
$$


The Cross-WLF model was used to find the curve fitting constants (Table 12) which are required for Moldex3D simulations. Melt viscosity was calculated using Equation (3.9)

$$
\eta=\frac{\eta_{0}}{1+\left(\frac{\eta_{0} \gamma}{\tau^{*}}\right)^{1-n}}
$$

Zero shear viscosity was estimated using Equation (3.10)

$$
\eta_{0}=D_{1} \exp \left[-\frac{A_{1}\left(T-T^{*}\right)}{A_{2}+\left(T-T^{*}\right)}\right]
$$

\section{Table 12: Viscosity constants}

\begin{tabular}{ccc}
\hline \multirow{2}{*}{$\begin{array}{c}\text { Cross-WLF } \\
\text { constants }\end{array}$} & \multicolumn{2}{c}{ Powder vol \% } \\
\cline { 2 - 3 } $\boldsymbol{n}$ & $\mathbf{0}$ (Binder) & $\mathbf{5 2}$ \\
$\boldsymbol{\tau}^{*}, \boldsymbol{P a}$ & $\mathbf{0 . 4 0}$ & 0.40 \\
$\boldsymbol{D}_{\boldsymbol{1}}, \boldsymbol{P a} \cdot \boldsymbol{s}$ & $\mathbf{7 9 3}$ & 74145 \\
$\boldsymbol{T}^{*}, \boldsymbol{K}$ & $\mathbf{4 3 3 . 0 0} \mathbf{1 0}$ & $2.28 \times 10^{16}$ \\
$\boldsymbol{A}_{\boldsymbol{l}}$ & $\mathbf{7 8 . 1 3}$ & 372.08 \\
$\boldsymbol{A}_{\mathbf{2}}, \boldsymbol{K}$ & $\mathbf{5 1 . 6 0}$ & 52.65 \\
\hline
\end{tabular}

\subsubsection{EXPERIMENTS AND SIMULATIONS}

Injection molding experiment listed in table 1 was performed with injection velocity of 120 $\mathrm{mm} / \mathrm{s}$ and packing pressure of $40 \mathrm{MPa}$ and a melt temperature of $160^{\circ} \mathrm{C}$ with $\mathrm{PZT}$ feedstock. The experiments resulted in $100 \%$ filled parts with well-defined micro pillars. 


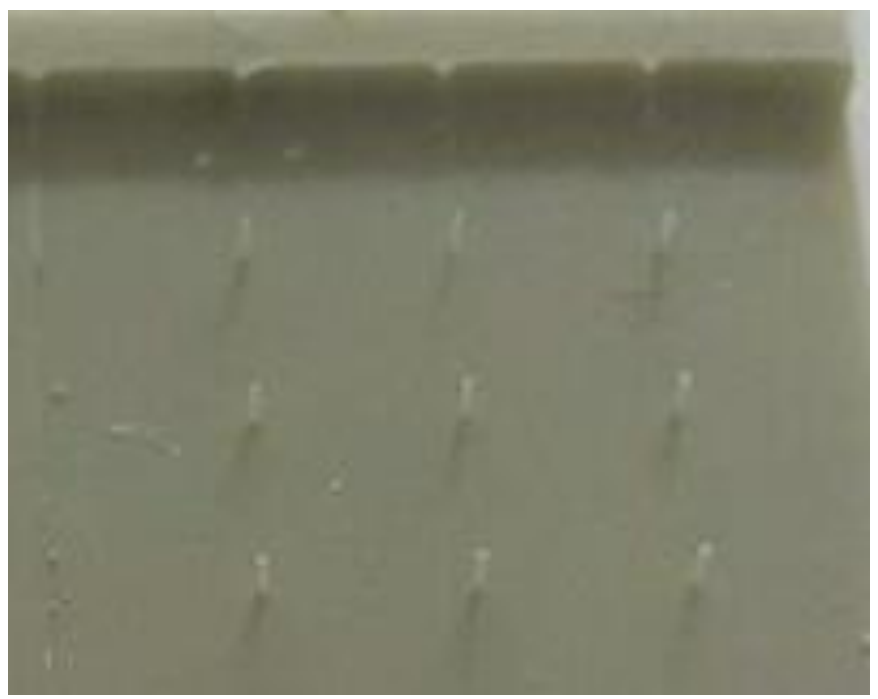

Figure 11: Sintered Microarray part

Using feedstock material properties constants from Table 10 to Table 12, material database file was created in Moldex3D software. In order to check the effectiveness of PIM simulations in predicting mold filling behavior, simulations were then performed on the meshed part file Figure $\mathbf{1 0}$ using material database file, and process conditions from experiments. The simulations successfully confirmed the mold filling behavior with $100 \%$ filled microarray. In simulations, during mold filling it is observed that the base plate is filled completely in $\mathrm{x}-\mathrm{y}$ direction and when the melt front hits end of fill, the material is filled in microarray pillars along the $\mathrm{z}$ direction. 

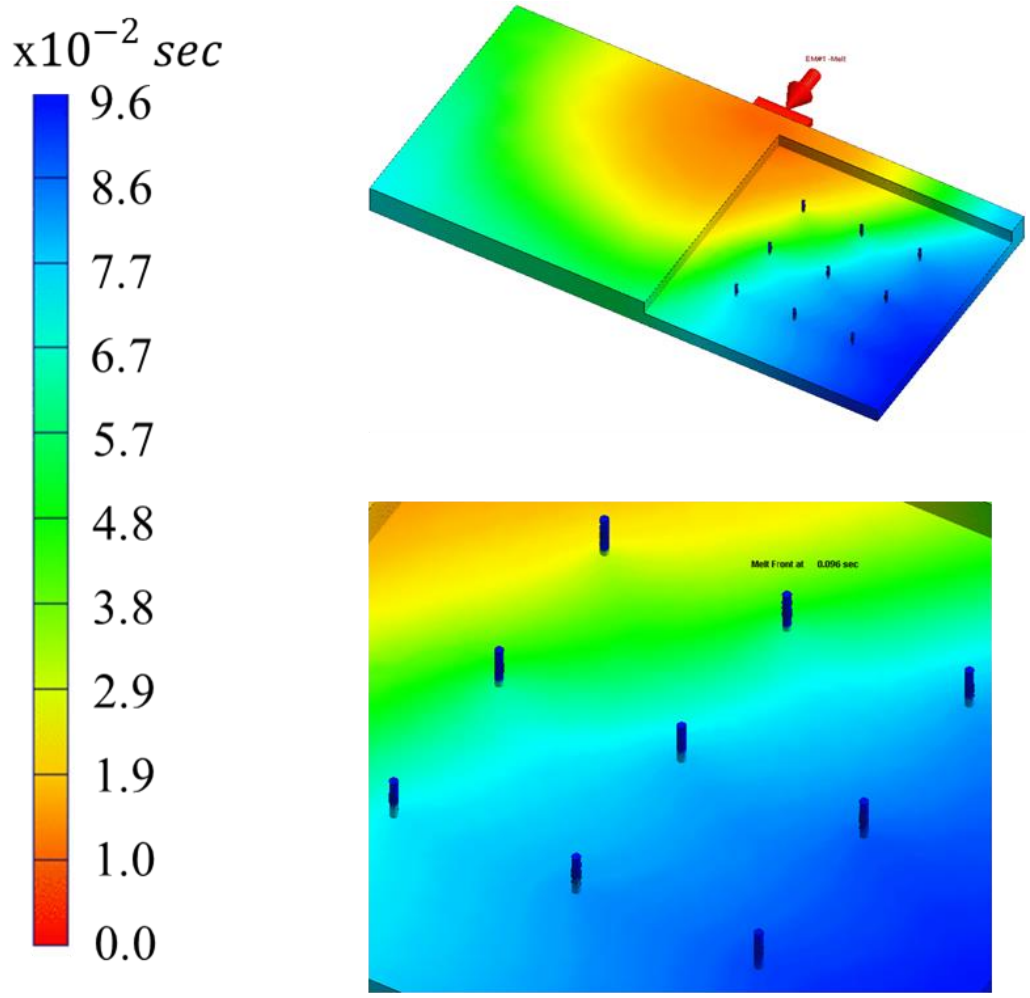

Figure 12: Mold filling behavior in microarray

Table 13: Comparison of part weight with experiments and simulations

\begin{tabular}{cc}
\hline \multicolumn{2}{c}{ Green body - Part weight } \\
\hline Experiments & Simulations \\
$4.02 \mathrm{gm}$ & $\mathbf{4 . 6 2} \mathbf{~ g m}$ \\
\hline
\end{tabular}

Table 14: Comparison of linear shrinkage in experiments and simulations

\section{Linear Shrinkage}

\begin{tabular}{cc}
\hline Experiments & Simulations \\
$1.33 \%$ & $\mathbf{1 . 3 8 \%}$ \\
\hline
\end{tabular}




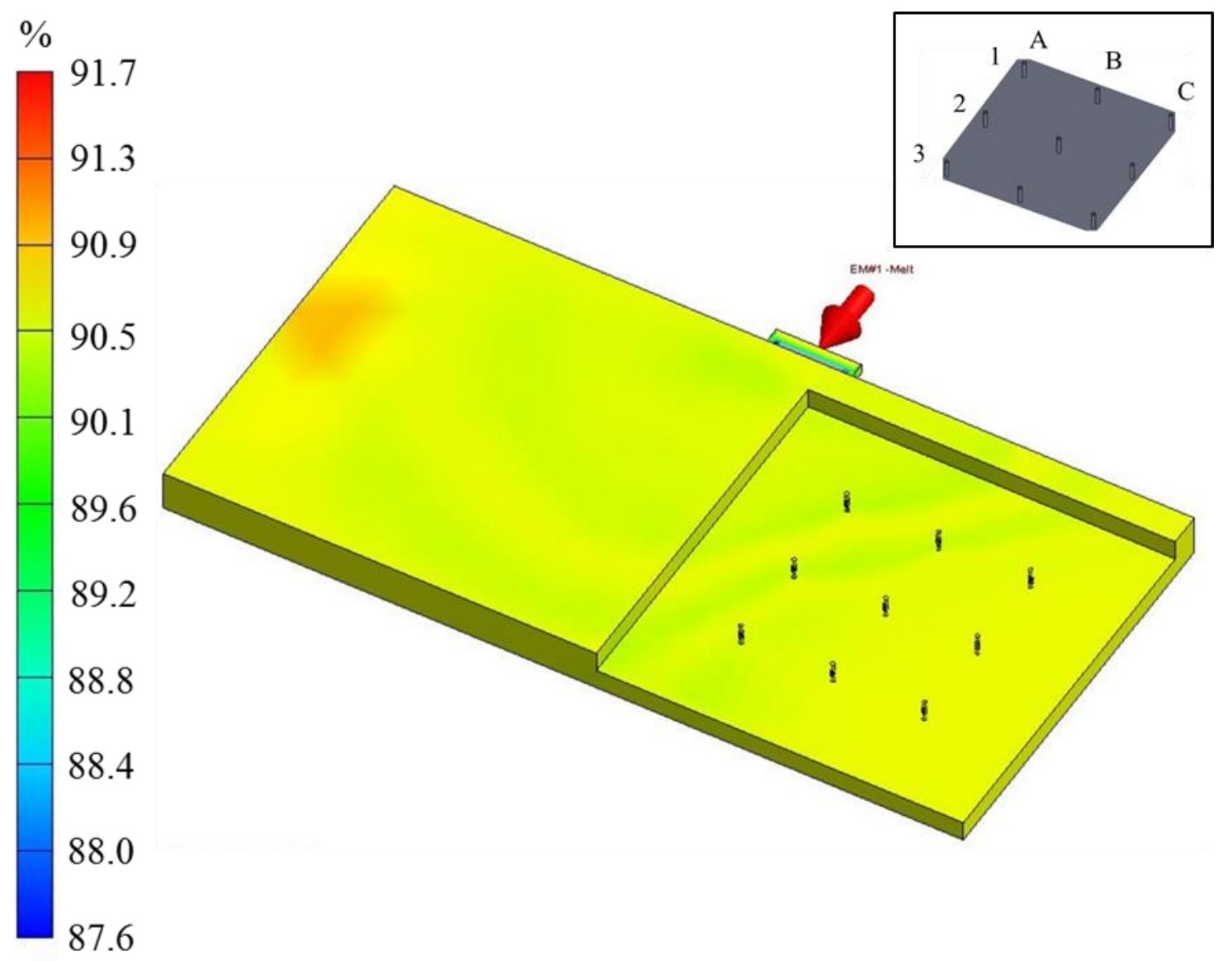

Figure 13: Powder concentration of filled and packed microarray

Powder concentration in the feedstock is $90.06 \%$. During the injection molding simulations it is observed that the powder concentration varies from $87.6 \%$ to $91.7 \%$. As seen in figure

5 , powder concentration varies with the flow front, with green, yellow and red patched indicating variation in powder concentration. The overall powder concentration looks uniform throughout the surface. 


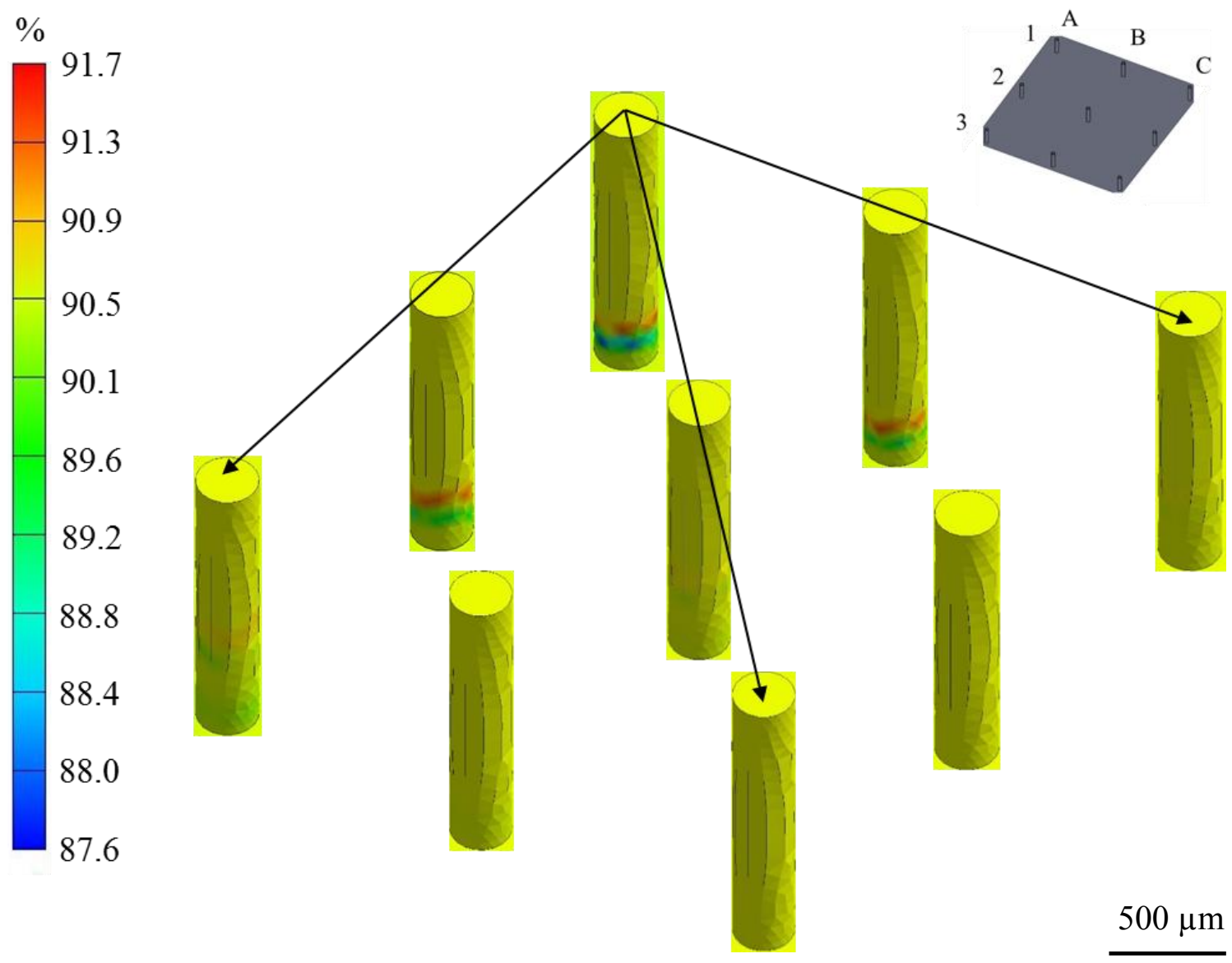

Figure 14: Powder concentration within individual micro-pillars

When the individual micro pillars were closely examined, a lower powder concentration was observed at the bottom of micro pillars as shown in Figure 15. A trend was observed in the powder concentration within micro pillars which can be seen in Figure 14. Figure 14 represents the powder concentration in each micro pillar and it can be observed that as you move away from the gate location, the powder concentration becomes more uniform. It can also be implied that micro pillar closest to the gate location has highest amount of variation in powder concentration and the micro pillar farthest from the gate location has least amount of variation. 


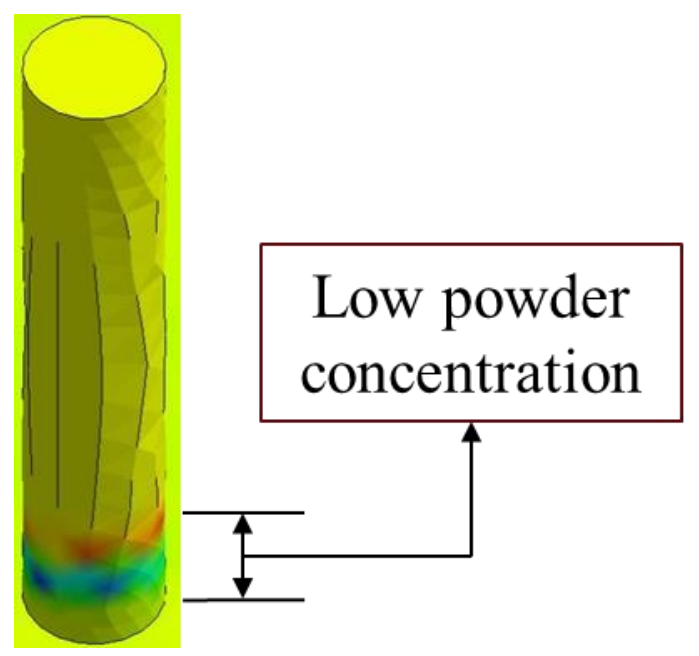

Figure 15: Powder concentration of micro-pillar at location A1

The defect of broken micro pillar during sintering, observed in Figure 19, can be attributed to the variation in powder concentration seen during simulations. As the powder concentration at the bottom of micro pillar is less, it will lead to non-uniform shrinkage within the micro-pillar during debinding and sintering of green body. It will result in neck formation in the region of low powder concentration and thus more susceptible to failure.

More detailed study was performed to reason the variation of powder concentration. In simulation, a cross section was taken at the region of low powder concentration $(1.08 \mathrm{~mm}$ from bottom of base plate) to observe temperature distribution in the microarray configuration during filling. This temperature during mold filling behavior is represented in . It was observed that the temperature during filling varies with the location of micro pillar from the gate location. The micro pillar closest to the gate location had the lowest filling temperature. And the micro pillar farthest away from the gate location had the highest filling temperature. 


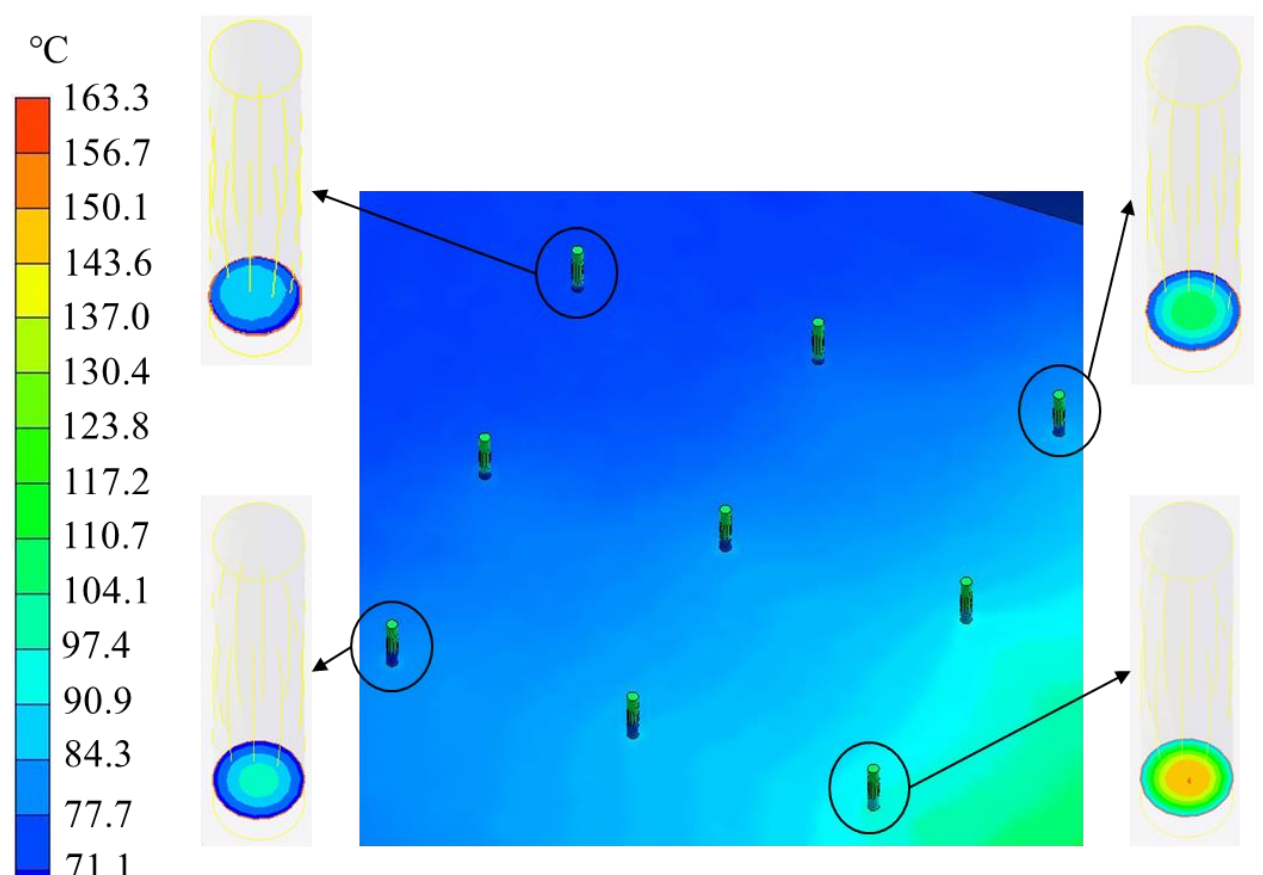

71.1

64.5

Figure 16: Temperature during filling at bottom of micro-pillar

-120-130 $=110-120=100-110=90-100=80-90$

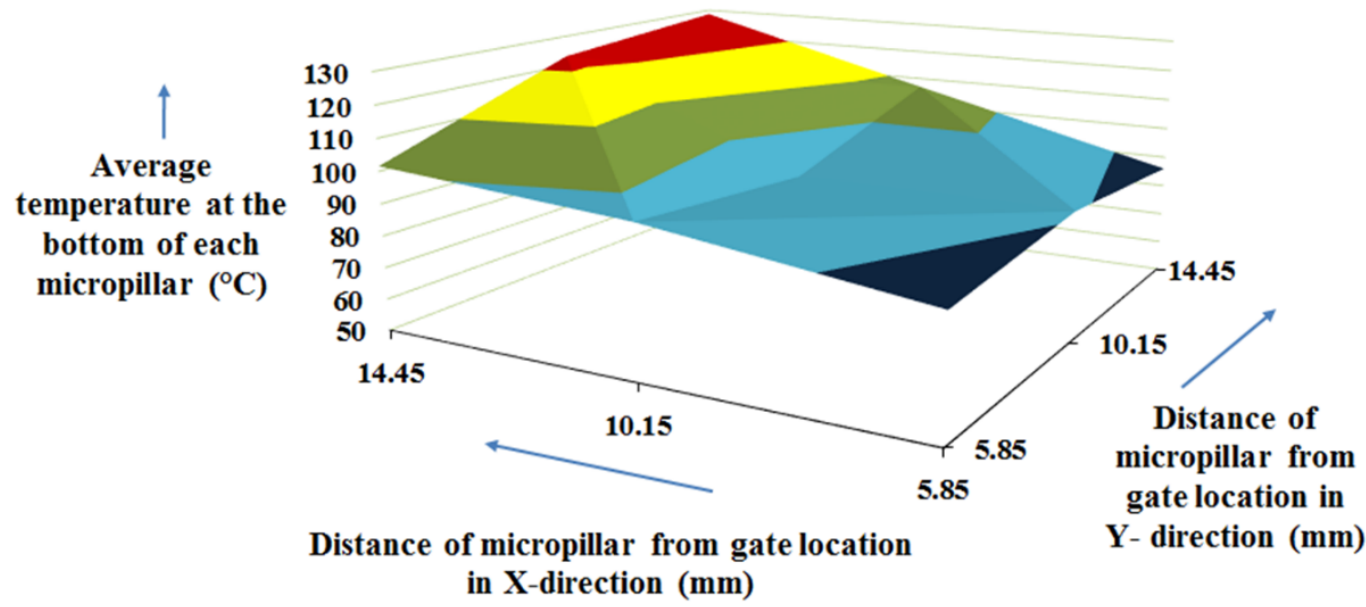

Figure 17: 3D plot of temperature distribution within micro-pillar with respect to its distance from gate location 
To further understand this phenomenon, mold filling temperature distribution within a micro pillar was 3D plotted against its $\mathrm{x}$ and $\mathrm{y}$ distance from the gate location as shown in Figure 17. The graph observed is an inclined 3D surface, with increase in $x$ and $y$ distance, the temperature distribution within the micro pillar significantly increases.

When the powder concentration was investigated at the same cross section, a similar 3D graph was plotted with powder concentration \% on Z-axis as shown in Figure 18.

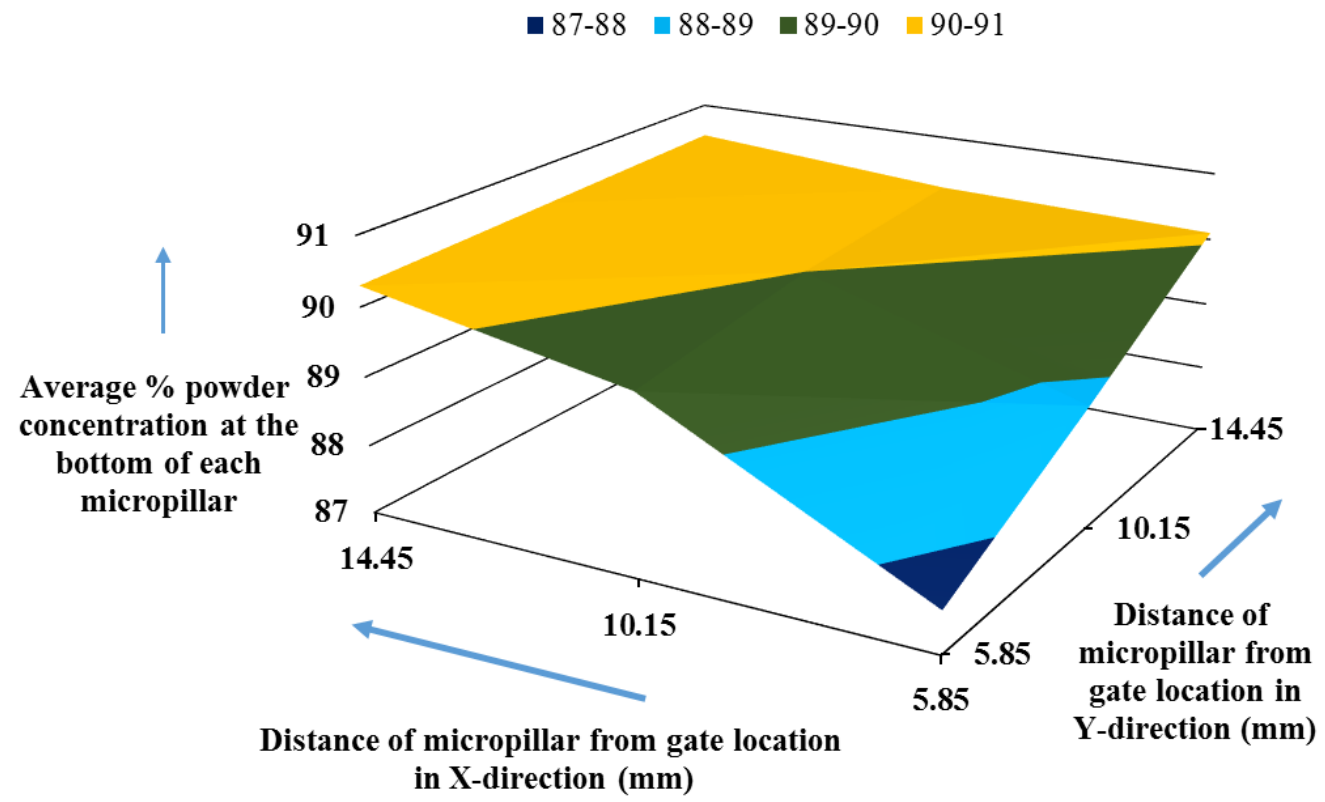

Figure 18: 3D plot of $\%$ powder concentration with respect to its distance from gate location

The powder concentration of the PZT feedstock is $90.06 \%$. The micro pillars with filling temperature range from 80 to $90^{\circ} \mathrm{C}$ have powder concentration of 87 to $88 \%$; 90 to $100^{\circ} \mathrm{C}$ have powder concentration of 88 to $90 \%$ and 100 to $130^{\circ} \mathrm{C}$ have powder concentration of 90 to $91 \%$. 

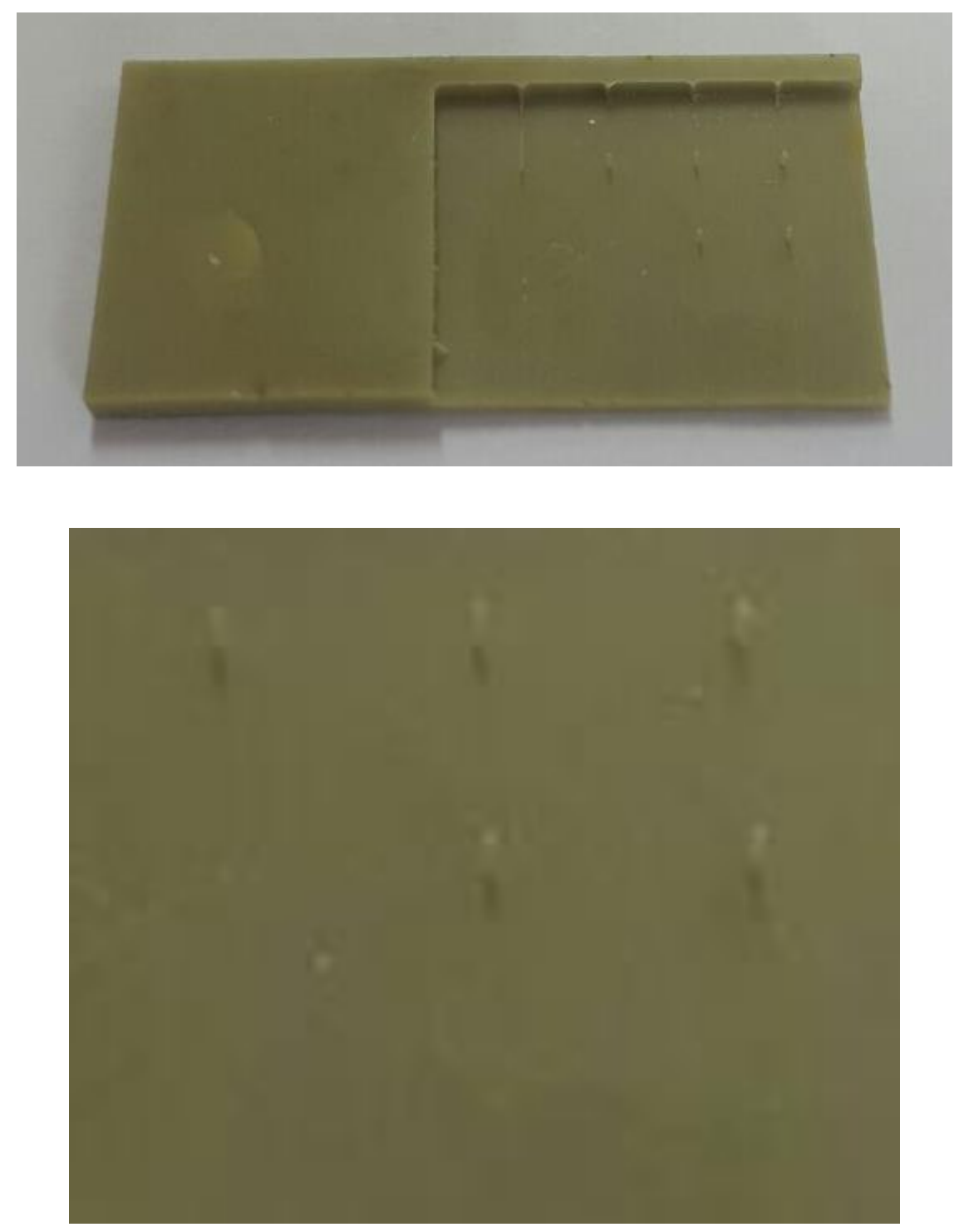

Figure 19: Broken micro pillars after sintering

From these studies it can be said that, powder concentration is attributed to the mold filling temperature. Lower the mold filling temperature with respect to average filling temperature, lower is the powder concentration. Similarly, a higher filling temperature will lead to more uniform powder concentration. This non-unifrom powder concentation will cause to various molding defects such as distortion, cracks or voids. These defects during PIM in turn leads to non-uniform shrinkage or warping in the sintered parts $[5,12]$ 


\subsection{SUMMARY}

PZT feedstock for 52 vol. \% solids loading was successfully formulated and injection molding experiments were performed to get completely molded parts. To perform PIM simulations, physical, thermal, rheological properties and PVT parameters were estimated for 52 vol. \% PZT feedstock. Estimated PIM material properties were used as input parameters and PIM simulations were performed using same process conditions as that of PIM experiments process conditions. PIM simulations results indicate that injection molding behavior predicted with PIM simulations is comparable to the molding behavior with experiments. Completely filled microarray parts from PIM experiments and simulation using estimated were $5.26 \mathrm{gm}$ and $4.62 \mathrm{gm}$ respectively. Additionally, linear shrinkage predictions with PIM simulations using estimated materials properties $(1.38 \%)$ is comparable to PIM experiments (1.33\%). Using simulations, defects and non-uniform shrinkage during sintering is be predicted by the knowledge of powder concentration and filling temperature of each micro-pillar. 


\section{CONCLUSIONS}

With the use of above discussed feedstock model, the goal of reducing trial and errors in developing feedstock for PZT is successfully achieved. Furthermore, simulations can be used as a platform to predict and understanding mold flowing behavior. The results of experiments were in good compliance in with simulations.

- Feedstock properties estimated: PZT 45 vol. \% and 52 vol.

(density, thermal conductivity, specific heat viscosity and specific volume)

- Estimated PZT feedstock properties can be used to perform PIM simulations

- Simulations can predict mold filling behavior, part weight and shrinkage

Hence, simulations should be used as a starting point for PIM experiments. Understanding of powder concentration and its correlation to filling temperature is an indicator of possible defects in during actual experiments.

- Sintering defect can be related to powder concentration and temperature distribution

- But exact broken pillar location cannot be predicted

Hence, secondary goal of thesis is also met by predicting possible defects. Thus this research serve as a complete guideline to perform PIM for PZT from feedstock development to net-shape part. 


\section{FUTURE WORK}

In this entire study, the simulations were based on estimated material properties except in Chapter 2, where hybrid material properties were also used. Such as approach can now be used in simulations using measured material properties based on micro pillar array and understand its proximity with experiments.

Experiments can now be conducted to study effect of change in microarray spacing and gate location. Simulations results are discussed in Appendix A, B and C.

Another study can be conducted, is on the debinding and sintering behavior of the PZT ceramic. As during sintering, ceramics usually shrink more than $15 \%$, the knowledge of this behavior will help in designing complex geometries from PZT.

The microarray can further be tested for its dielectric constants, piezoelectric co-efficients and electromechanical coupling. These tested values can then be compared with literature. If a subsequent increase in these piezoelectric properties is observed, then this geometry can be utilized in developing sensors and actuator for ultrasound transducer. 


\section{REFERENCES}

1. EgÉSz, Á., and GÖMze, L.A. (2013). Measurable properties of Al2O3 ceramic injection molding raw materials. A12O3 kerámia fröccsöntés alapanyagának vizsgálatai. $65,107-111$.

2. Mohd Foudzi, F., Muhamad, N., Bakar Sulong, A., and Zakaria, H. (2013). Yttria stabilized zirconia formed by micro ceramic injection molding: Rheological properties and debinding effects on the sintered part. Ceramics International 39, 2665-2674.

3. Piotter, V., Gietzelt, T., and Merz, L. (2003). Micro powder-injection moulding of metals and ceramics. Sadhana 28, 299-306.

4. Ruprecht, R., Gietzelt, T., Müller, K., Piotter, V., and Haußelt, J. (2002). Injection molding of microstructured components from plastics, metals and ceramics. Microsystem Technologies 8, 351-358.

5. Supati, R., Loh, N.H., Khor, K.A., and Tor, S.B. (2000). Mixing and characterization of feedstock for powder injection molding. Materials Letters 46, 109-114.

6. Seung-Eek, P., and Shrout, T.R. (1997). Characteristics of relaxor-based piezoelectric single crystals for ultrasonic transducers. IEEE Transactions on Ultrasonics, Ferroelectrics, and Frequency Control 44, 1140-1147. 
7. Safari, A., Janas, V.F., and Bandyopadhyay, A. (1997). Development of fine-scale piezoelectric composites for transducers. AIChE Journal 43, 2849-2856.

8. Jiao, Z., Wan, X., Guo, H., Wang, J., Zhao, B., and Wu, M. (2008). The charge storage characteristics of PZT nanocrystal thin film. Ultramicroscopy 108, 13711373.

9. Juan, P.C., Jiang, J.D., Shih, W.C., and Lee, J.Y.M. (2007). The effect of annealing temperature on the electrical properties of metal-ferroelectric (PbZr0.53Ti0.47O3)-insulator (ZrO2)-semiconductor (MFIS) thin-film capacitors. Microelectronic Engineering 84, 2014-2017.

10. Liu, B.T., Zhang, X., Zhang, W.T., Yan, Z., Cheng, C.S., Li, F., Li, L., and Zhao, Q.X. (2007). Comparison of $\mathrm{Pb}(\mathrm{Zr}, \mathrm{Ti}) \mathrm{O} 3$ capacitors sandwiched with conductive $\mathrm{La} 0.5 \mathrm{Sr} 0.5 \mathrm{CoO} 3$ and non-conductive $\mathrm{Bi} 3.25 \mathrm{La} 0.75 \mathrm{Ti} 3 \mathrm{O} 12$ layers. Materials Letters 61, 3045-3047.

11. Mirza, M.S., Liu, Q., Yasin, T., Qi, X., Li, J.-F., and Ikram, M. (2016). Dice-andfill processing and characterization of microscale and high-aspect-ratio (K, $\mathrm{Na)NbO3-based} \mathrm{1-3} \mathrm{lead-free} \mathrm{piezoelectric} \mathrm{composites.} \mathrm{Ceramics} \mathrm{International}$ $42,10745-10750$.

12. Kate, K.H., Enneti, R.K., Onbattuvelli, V.P., and Atre, S.V. (2013). Feedstock properties and injection molding simulations of bimodal mixtures of nanoscale and microscale aluminum nitride. Ceramics International 39, 6887-6897.

13. Haertling, G.H. (1999). Ferroelectric ceramics: history and technology. Journal of the American Ceramic Society 82, 797-818. 
14. Newnham, R.E., Bowen, L.J., Klicker, K.A., and Cross, L.E. (1980). Composite piezoelectric transducers. Materials \& Design 2, 93-106.

15. Han, J.S., Gal, C.W., Kim, J.H., and Park, S.J. (2016). Fabrication of high-aspectratio micro piezoelectric array by powder injection molding. Ceramics International 42, 9475-9481.

16. Janas, V.F., and Safari, A. (1995). Overview of fine-scale piezoelectric ceramic/polymer composite processing. Journal of the American Ceramic Society $78,2945-2955$.

17. Takahashi, S., Hirose, S., and Uchino, K. (1994). Stability of PZT piezoelectric ceramics under vibration level change. Journal of the American Ceramic Society $77,2429-2432$.

18. Safari, A. (1994). Development of piezoelectric composites for transducers. Journal de Physique III 4, 1129-1149.

19. Lous, G.M., Cornejo, I.A., McNulty, T.F., Safari, A., and Danforth, S.C. (2000). Fabrication of piezoelectric ceramic/polymer composite transducers using fused deposition of ceramics. Journal of the American Ceramic Society 83, 124-128.

20. Kate, K.H., Onbattuvelli, V.P., Enneti, R.K., Lee, S.W., Park, S.-J., and Atre, S.V. (2012). Measurements of powder-polymer mixture properties and their use in powder injection molding simulations for aluminum nitride. JOM 64, 1048-1058.

21. Onbattuvelli, V.P., Vallury, S., McCabe, T., Park, S.J., and Atre, S.V. (2010). Properties of SiC and AlN feedstocks for the powder injection moulding of thermal management devices. Powder Injection Moulding International 4, 64-70.

22. Nielsen, L.E. (1978). Predicting the properties of mixtures, (M. Dekker). 
23. Boudenne, A., Ibos, L., Fois, M., Gehin, E., and Majeste, J.C. (2004).

Thermophysical properties of polypropylene/aluminum composites. Journal of Polymer Science Part B: Polymer Physics 42, 722-732.

24. Jamieson, D.T., and Cartwright, G. (1978). Properties of binary liquid mixtures: heat capacity, (National Engineering Laboratory).

25. Weidenfeller, B., Höfer, M., and Schilling, F.R. (2004). Thermal conductivity, thermal diffusivity, and specific heat capacity of particle filled polypropylene. Composites Part A: applied science and manufacturing 35, 423-429.

26. Subodh, G., Manjusha, M., Philip, J., and Sebastian, M. (2008). Thermal properties of polytetrafluoroethylene/Sr2Ce2Ti5O16 polymer/ceramic composites. Journal of Applied Polymer Science 108, 1716-1721.

27. Wong, C., and Bollampally, R.S. (1999). Thermal conductivity, elastic modulus, and coefficient of thermal expansion of polymer composites filled with ceramic particles for electronic packaging. Journal of Applied Polymer Science 74, 33963403.

28. Onbattuvelli, V.P. (2010). The effects of nanoparticle addition on the processing, structure and properties of $\mathrm{SiC}$ and $\mathrm{AlN}$.

29. Shi, X.Z., Huang, M., Zhao, Z.F., and Shen, C.Y. (2011). Nonlinear fitting technology of 7-parameter cross-wlf viscosity model. In Advanced Materials Research, Volume 189. (Trans Tech Publ), pp. 2103-2106.

30. German, R.M. (1994). Homogeneity Effects on Feedstock Viscosity in Powder Injection Molding. Journal of the American Ceramic Society 77, 283-285. 


\section{APPENDIX}

(A) CAD models and process conditions for simulations

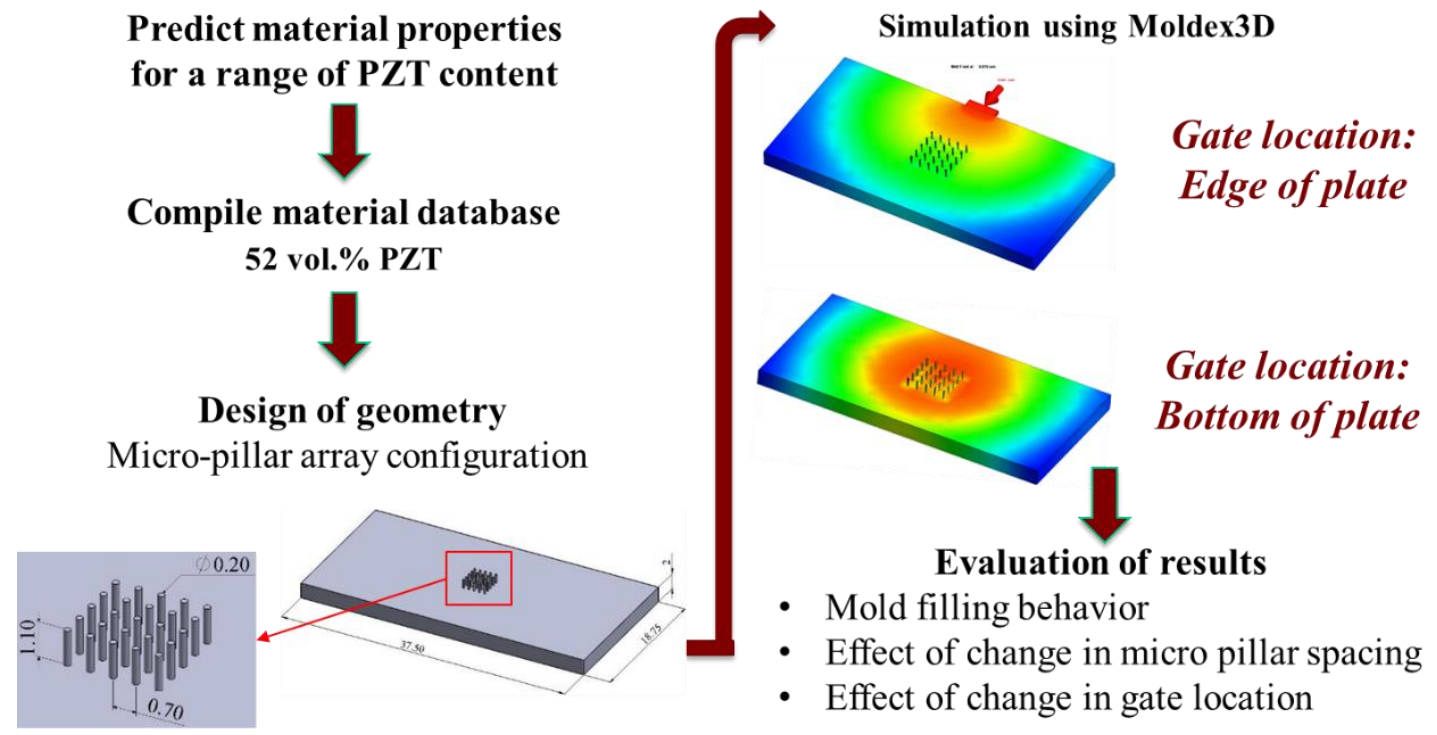

Figure 20: Flow chart for simulations

Figure 20 represents the flow chart used in study of micro-pillar array geometry. Material properties such as density, specific heat, thermal conductivity, viscosity and specific volume were estimated using semi-empirical models. Using the estimated material properties, constants were extracted for simulations in Moldex3D. Microarray geometry was designed for a balanced flow PIM. These geometries were then studied for mold filling behavior, effect of change in microarray spacing and effect of change in gate location.

Using SolidWorks, three different microarray geometries were designed. Each geometry has a unique microarray spacing as shown in figure 21 . The base plate geometry and aspect 
ratio of the micro-pillar is kept constant in all three designs which is evident in figure 21 (a), (b) and (c).

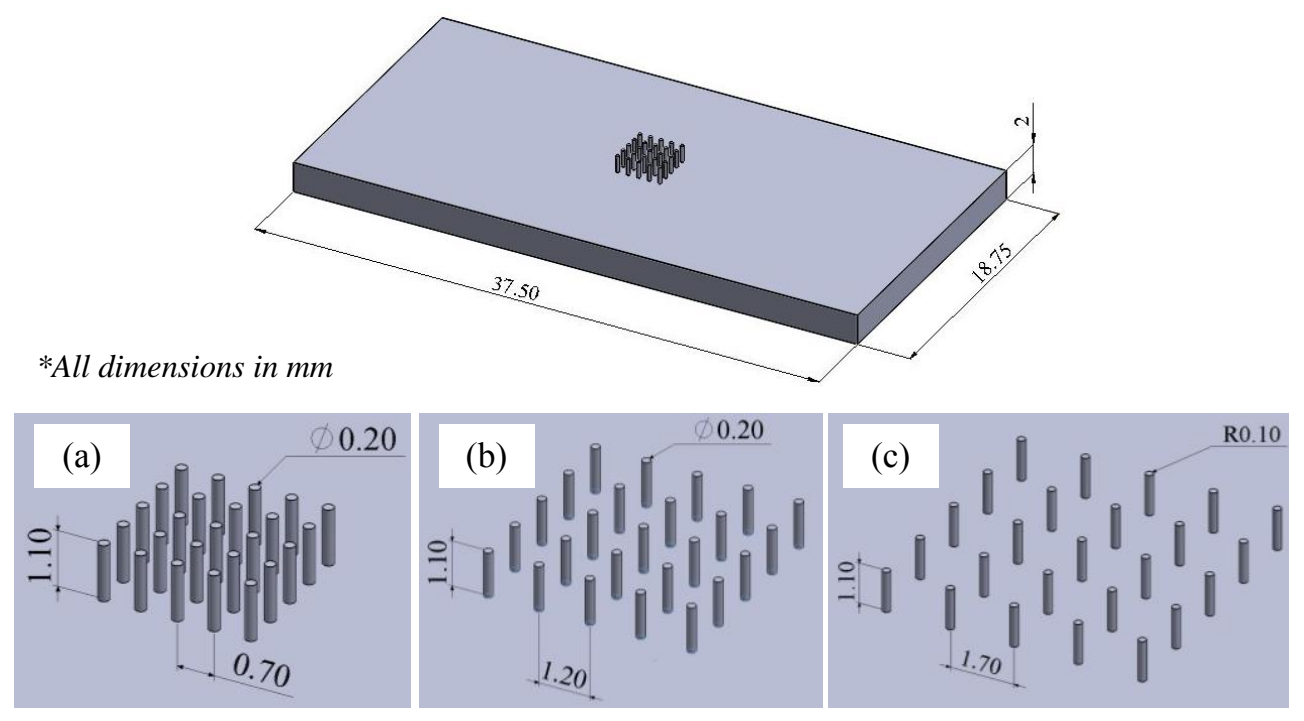

Figure 21: Microarray geometry (CAD model) with inter-pillar spacing (a) $0.7 \mathrm{~mm}$ (b) $1.2 \mathrm{~mm}$ (c) $1.7 \mathrm{~mm}$

Each micro-pillar has diameter of $200 \mu \mathrm{m}$ and a height of $1100 \mu \mathrm{m}$ with inter-pillar spacing of $700 \mu \mathrm{m}, 1200 \mu \mathrm{m}$ and $1700 \mu \mathrm{m}$. These CAD model were then converted to .STEP file format for meshing them in Moldex3D software. During meshing, two different gate locations were used, namely, edge gate and bottom gate. Figure 22 represents the mesh file of microarray geometry with bottom gate location. 

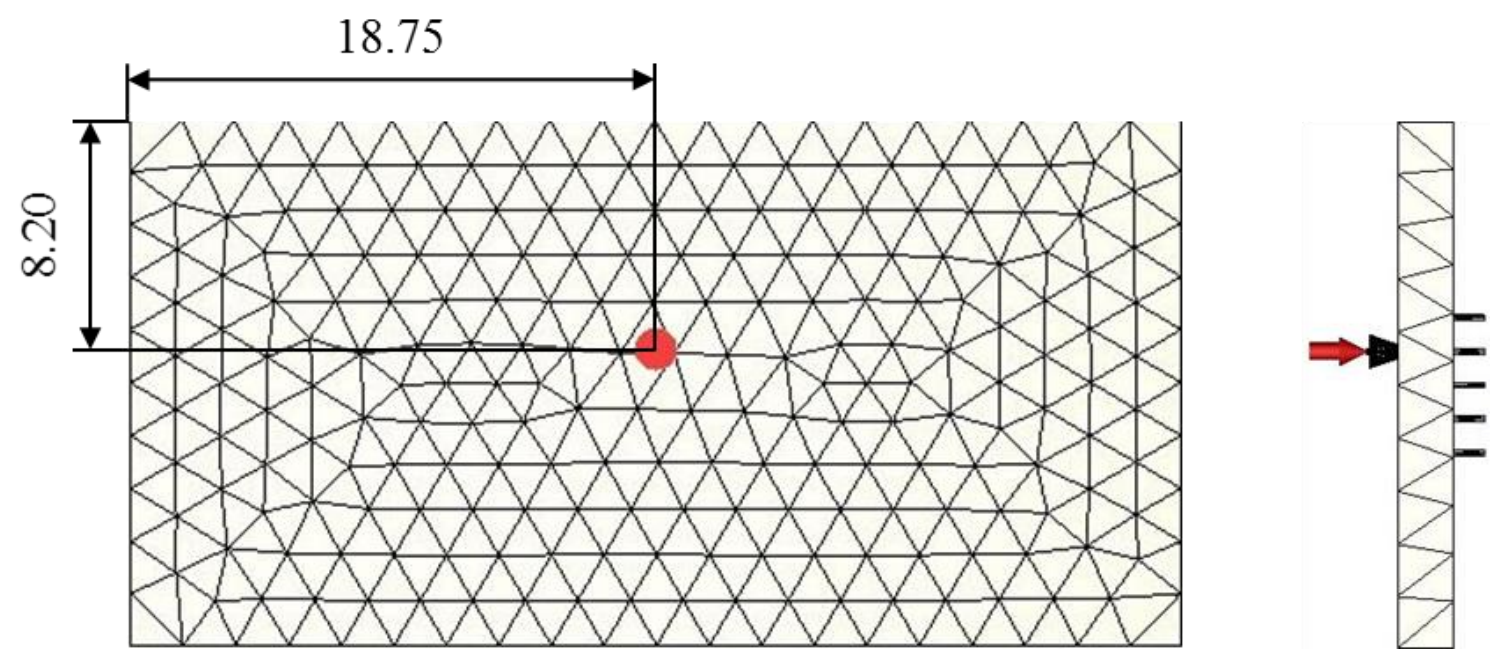

Figure 22: Bottom gate location on the mesh file (Moldex3D)

The bottom gate is purposefully offset from the face center of plate so as to avoid hesitation during mold filling for microarray geometry.

Table 15: PIM process conditions

\begin{tabular}{lc}
\hline \multicolumn{1}{c}{ Process Parameters } & Values \\
\hline Mold temperature, ${ }^{\circ} \mathrm{C}$ & 45 \\
Melt temperature, ${ }^{\circ} \mathrm{C}$ & 160 \\
Ram position, mm & 25 \\
Injection Velocity, mm/s & 90 \\
Packing pressure 1, MPa for 8s & 40 \\
Packing pressure 2, MPa for 4 s & 30 \\
\hline
\end{tabular}

The simulations were setup using the process conditions shown in Table 8 . 
(B) Effect of change in microarray spacing

1. Mold filling behavior

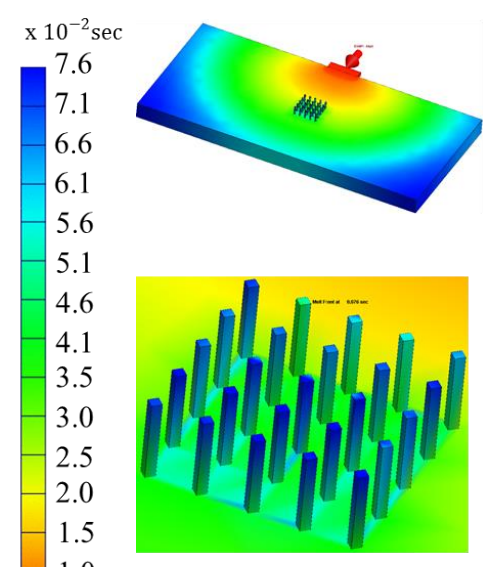

Spacing: $0.7 \mathrm{~mm}$
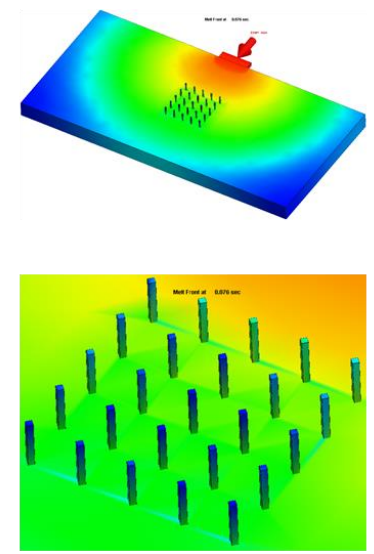

Spacing: $1.2 \mathrm{~mm}$
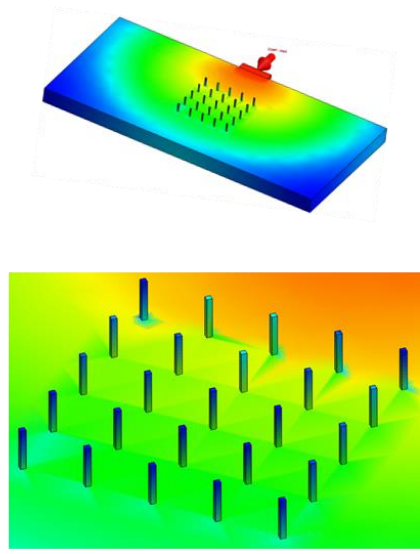

Spacing: $1.7 \mathrm{~mm}$

Figure 23: Mold filling behavior for change in microarray spacing

The effect of change in microarray spacing on mold filling behavior is represented in figure

23. It is observed that all the micro pillars are completely filled having part weight of 5.88 gm. Although the fill time is same, it is observed that there is a significant difference in mold filling pattern for each microarray configuration. From simulations, one can conclude that when the microarray spacing is narrow, the flow front is unbalanced with some micropillars getting filled faster than the others. But as you increase the microarray spacing, the mold filling behavior becomes more uniform, with number of pillars filling together increases. 
2. Air traps

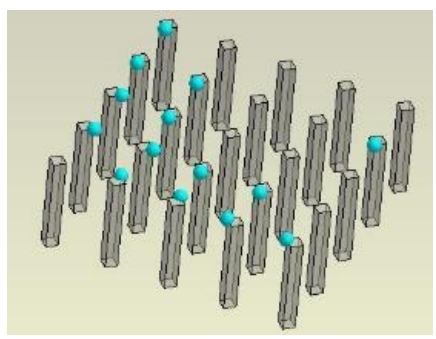

Spacing: $0.7 \mathrm{~mm}$, no. of air traps: 14

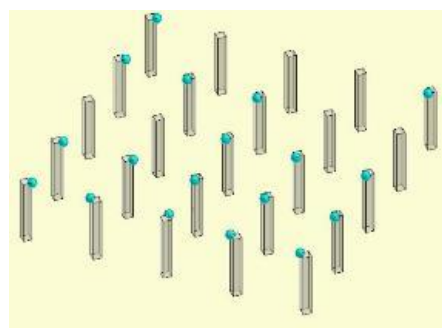

Spacing: $1.2 \mathrm{~mm}$, no. of air traps: 18

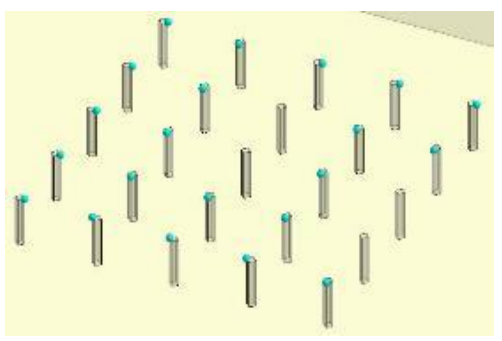

Spacing: $1.7 \mathrm{~mm}$, no. of air traps: 21

Figure 24: Air traps for change in microarray spacing

3. Powder concentration

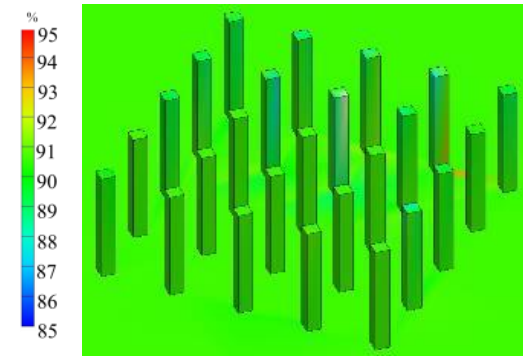

Spacing: $0.7 \mathrm{~mm}$

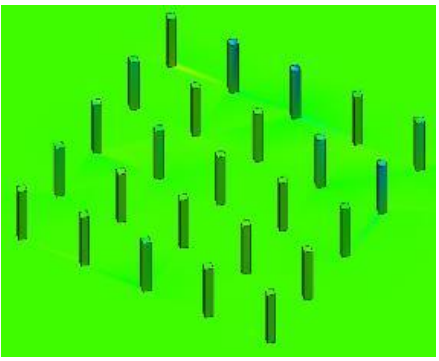

Spacing: $1.2 \mathrm{~mm}$

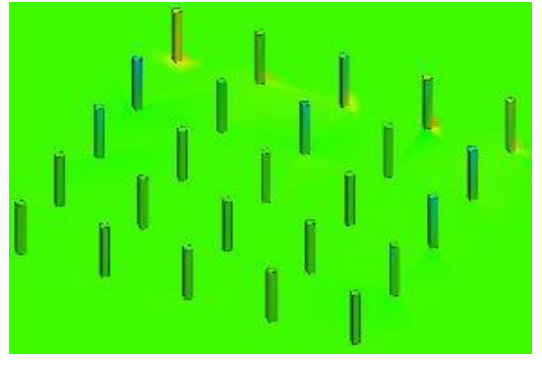

Spacing: $1.7 \mathrm{~mm}$

Figure 25: Powder concentration for change in microarray spacing 
(C) Effect of change in gate location

1. Mold filling behavior

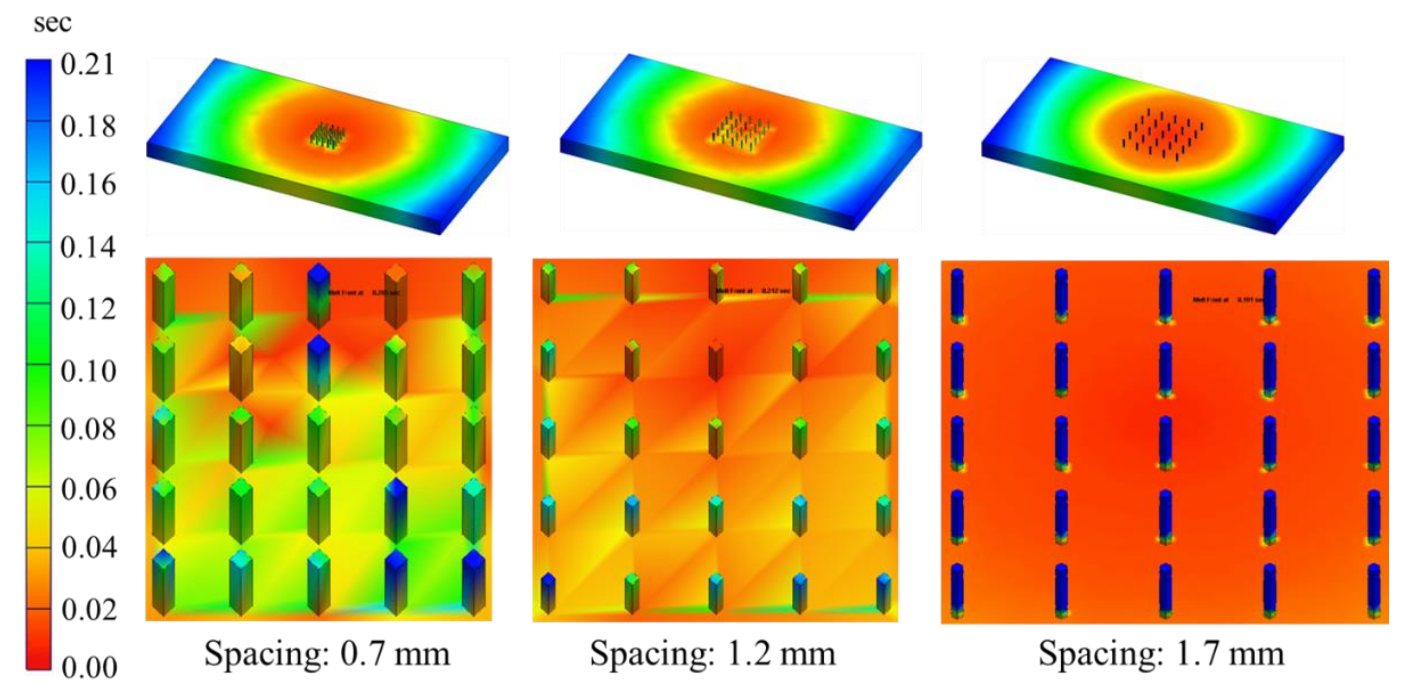

Figure 26: Mold filling behavior for change in gate location

2. Air traps

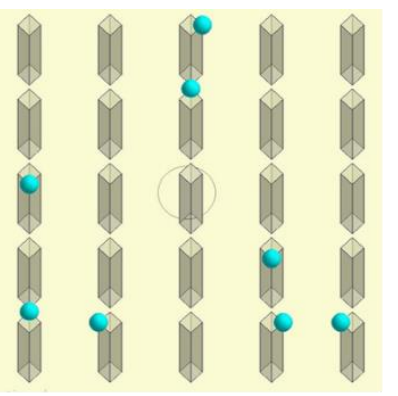

Spacing: $0.7 \mathrm{~mm}$ no. of air traps: 8

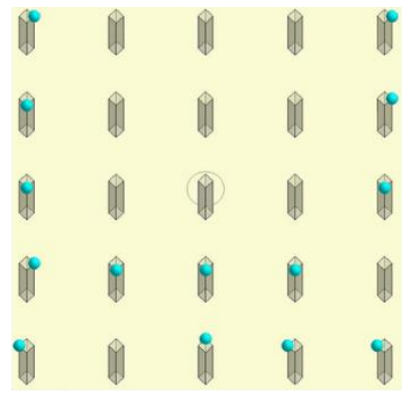

Spacing: $1.2 \mathrm{~mm}$ no of air traps: 14

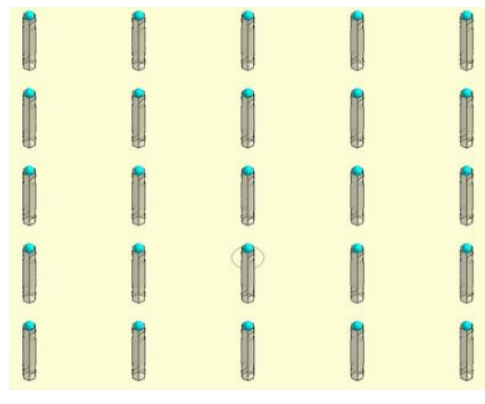

Spacing: $1.7 \mathrm{~mm}$ no of air traps: 25

Figure 27: Air traps for change in gate location 


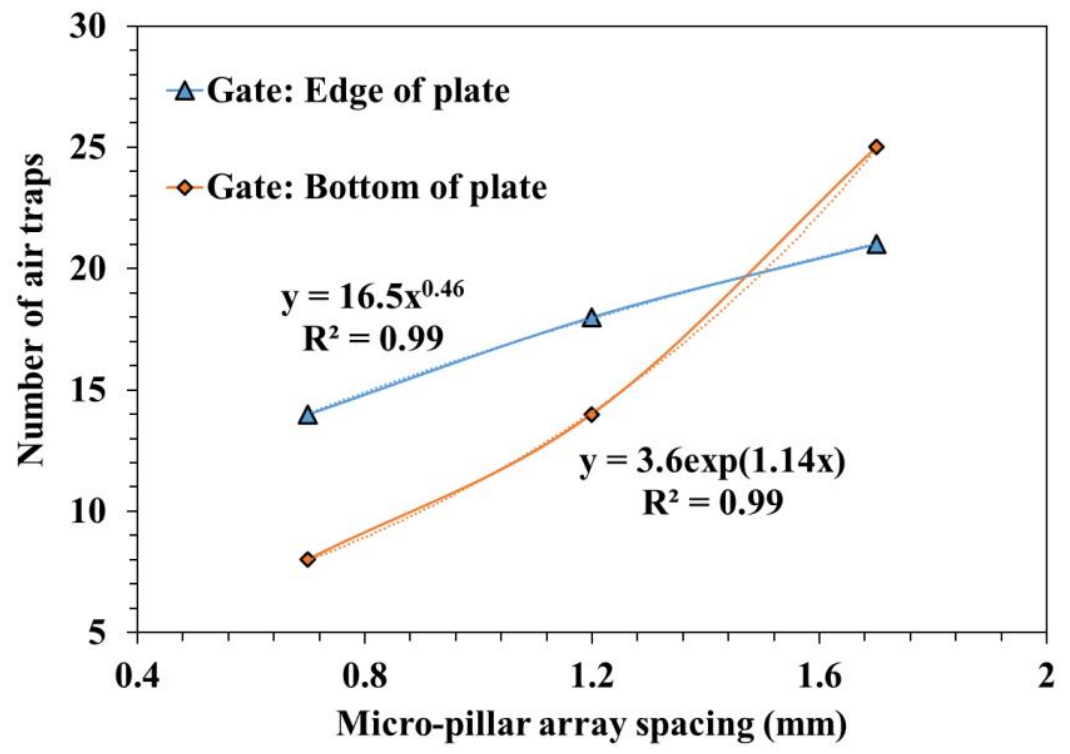

Figure 28: Comparison of air traps for different gate location

3. Powder concentration

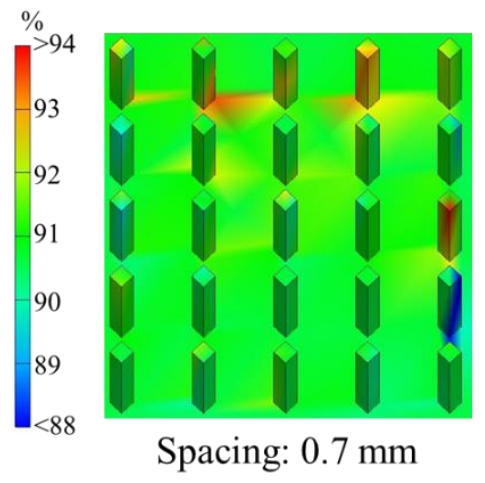

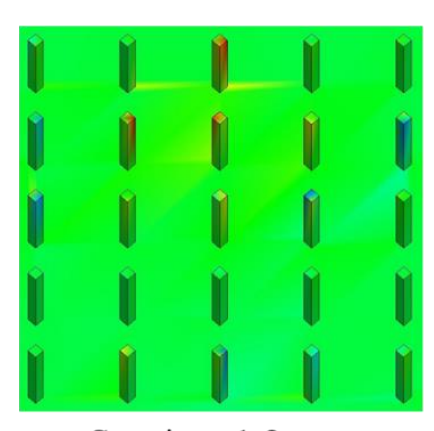

Spacing: $1.2 \mathrm{~mm}$

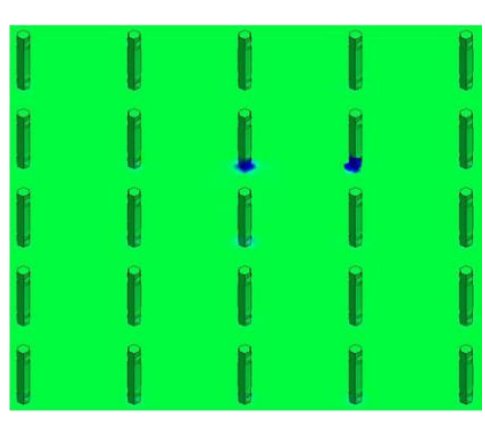

Spacing: $1.7 \mathrm{~mm}$

Figure 29: Powder concentration for change in gate location 
4. Shear stress

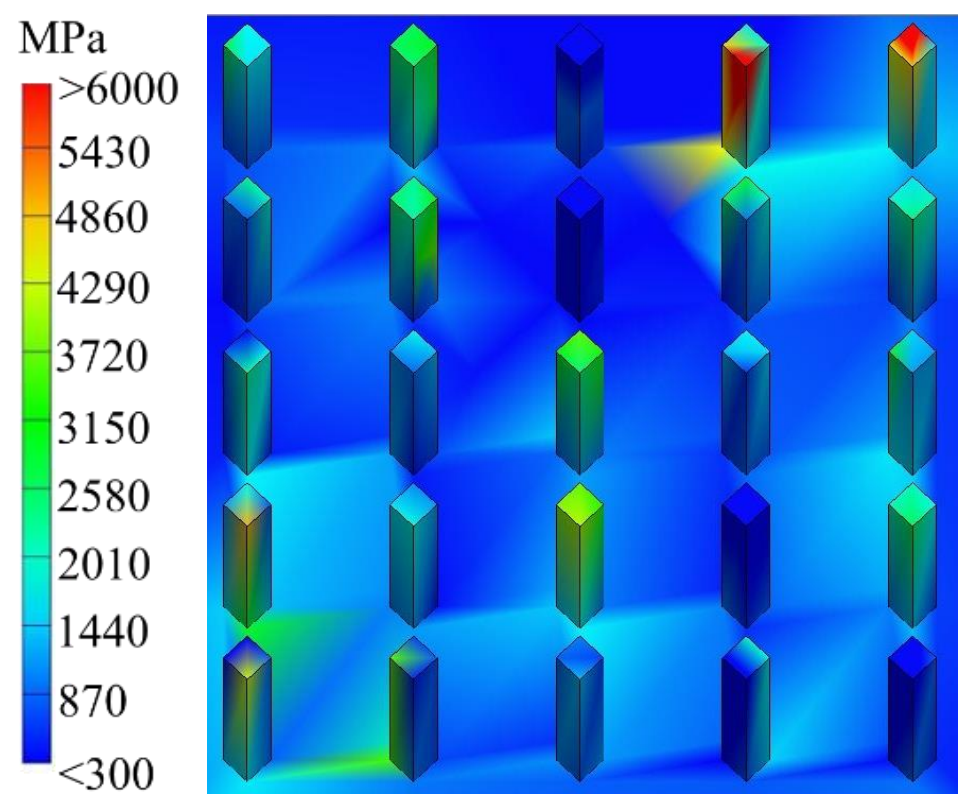

Figure 30: Shear stress for $0.7 \mathrm{~mm}$ microarray spacing with bottom gate

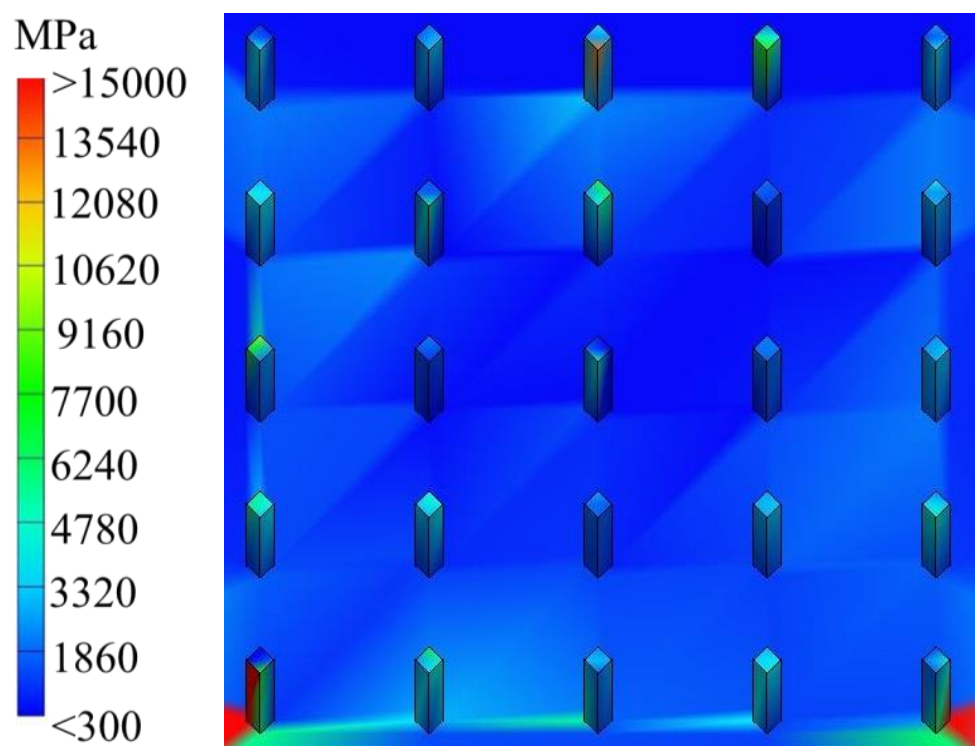

Figure 31: Shear stress for $1.2 \mathrm{~mm}$ microarray spacing with bottom gate 


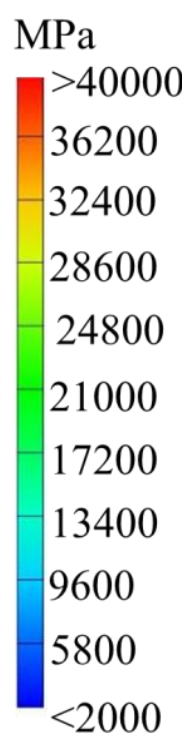

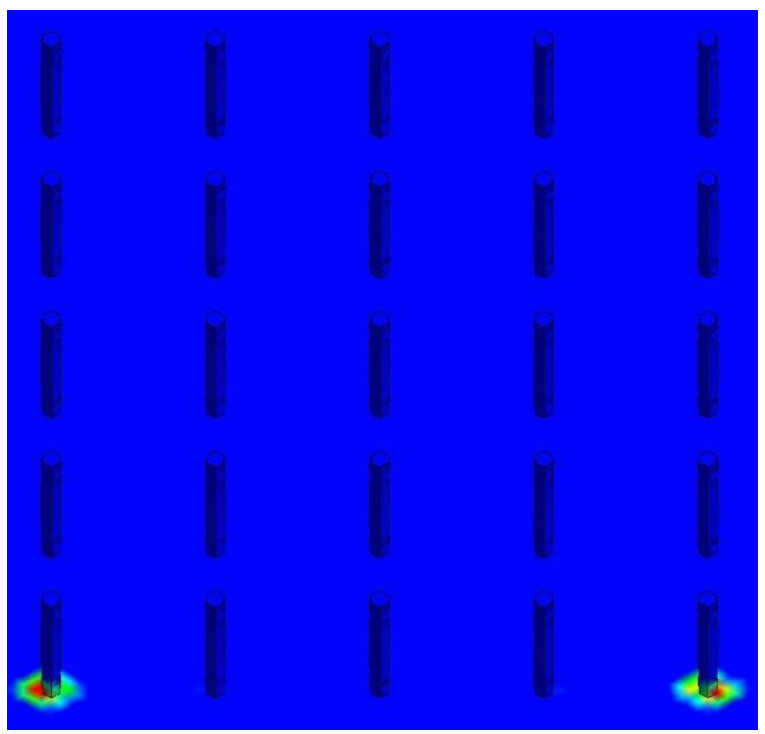

Figure 32: Shear stress for $1.7 \mathrm{~mm}$ microarray spacing with bottom gate 
(D) Rheology of powder-polymer composite

PZT 52 vol. \% WB50 rheology

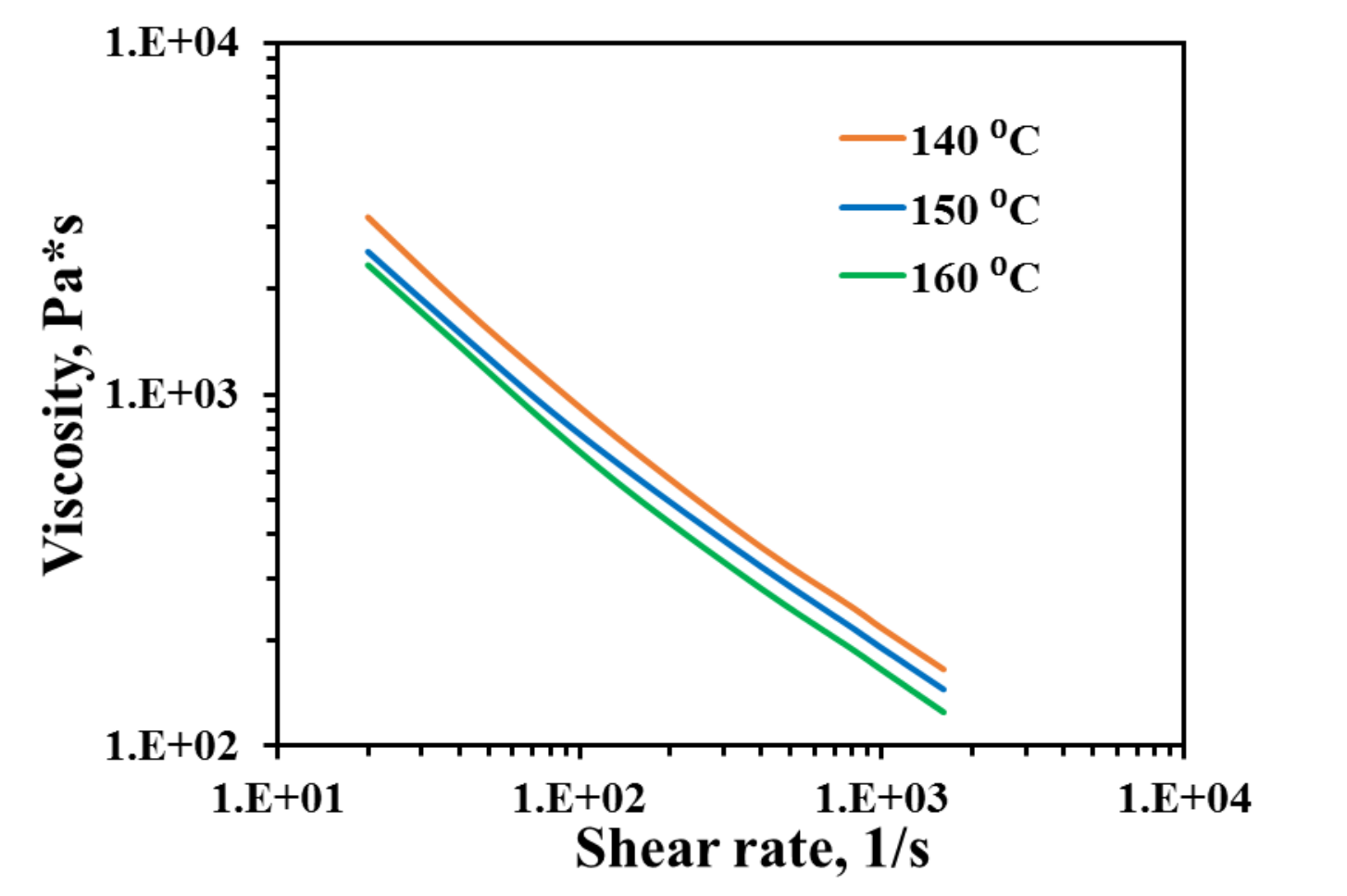

Figure 33: Measured viscosity of 52 vol. \% PZT with WB50 multicomponent binder

Table 16: Measured viscosity of 52 vol. \% PZT with WB50 multicomponent binder

\begin{tabular}{cccccc}
\hline \multicolumn{2}{c}{$\mathbf{1 4 0}^{\mathbf{0}} \mathbf{C}$} & \multicolumn{2}{c}{$\mathbf{1 5 0}^{\mathbf{}} \mathbf{C}$} & \multicolumn{2}{c}{$\mathbf{1 6 0}^{\mathbf{0}} \mathbf{C}$} \\
\hline $\begin{array}{c}\text { Shear } \\
\text { rate }\end{array}$ & Viscosity & $\begin{array}{c}\text { Shear } \\
\text { rate }\end{array}$ & Viscosity & $\begin{array}{c}\text { Shear } \\
\text { rate }\end{array}$ & Viscosity \\
\hline $\mathbf{s}^{-1}$ & Pa.s & $\mathrm{s}^{-1}$ & Pa.s & $\mathrm{s}^{-1}$ & Pa.s \\
\hline $\mathbf{2 0}$ & 3190.87 & 20 & 2543.93 & 20 & 2330.75 \\
\hline $\mathbf{4 0}$ & 1814.43 & 40 & 1500.43 & 40 & 1375.73 \\
\hline $\mathbf{8 0}$ & 1081.42 & 80 & 899.88 & 80 & 808.73 \\
\hline $\mathbf{1 6 0}$ & 664.25 & 160 & 567.56 & 160 & 496.95 \\
\hline $\mathbf{4 0 0}$ & 366.81 & 400 & 322.74 & 400 & 279.67 \\
\hline $\mathbf{8 0 0}$ & 247.60 & 800 & 216.31 & 800 & 187.98 \\
\hline $\mathbf{1 0 0 0}$ & 215.91 & 1000 & 189.59 & 1000 & 164.44 \\
\hline $\mathbf{1 6 0 0}$ & 165.07 & 1600 & 144.82 & 1600 & 124.67 \\
\hline & & & & & \\
\hline
\end{tabular}




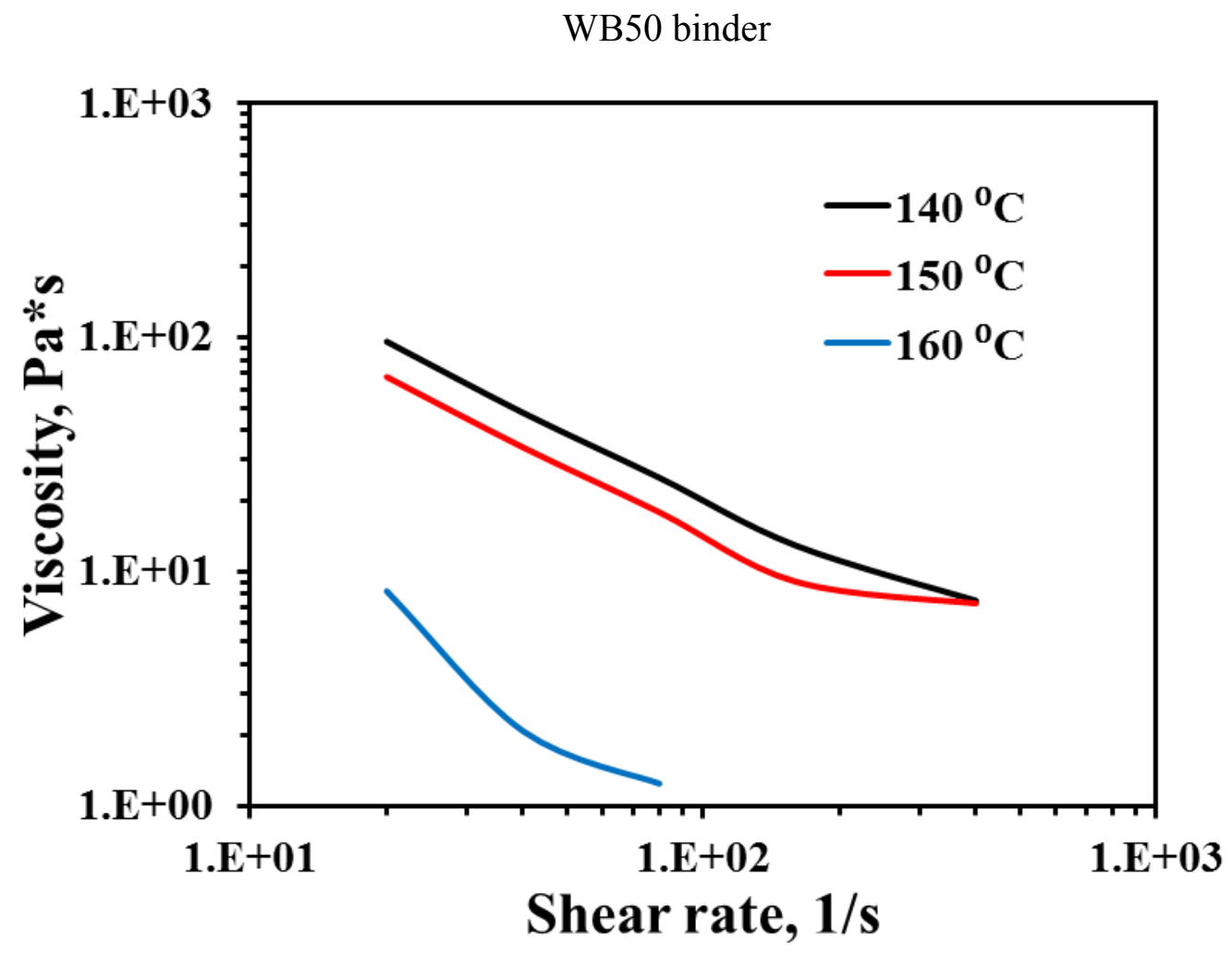

Figure 34: Measured viscosity of WB50 multicomponent binder

Table 17: Measured viscosity of WB50 multicomponent binder

\begin{tabular}{|c|c|c|c|c|c|}
\hline \multicolumn{2}{|c|}{$140^{\circ} \mathrm{C}$} & \multicolumn{2}{|c|}{$150^{\circ} \mathrm{C}$} & \multicolumn{2}{|c|}{$160^{\circ} \mathrm{C}$} \\
\hline $\begin{array}{c}\text { Shear } \\
\text { rate }\end{array}$ & Viscosity & $\begin{array}{c}\text { Shear } \\
\text { rate }\end{array}$ & Viscosity & $\begin{array}{c}\text { Shear } \\
\text { rate }\end{array}$ & Viscosity \\
\hline $\mathrm{s}^{-1}$ & Pa.s & $\mathrm{s}^{-1}$ & Pa.s & $\mathrm{s}^{-1}$ & Pa.s \\
\hline 20 & 95.73 & 20 & 67.67 & 20 & 8.24 \\
\hline 40 & 47.57 & 40 & 33.85 & 40 & 2.08 \\
\hline 80 & 25.12 & 80 & 17.89 & 80 & 1.24 \\
\hline 160 & 12.90 & 160 & 9.04 & 160 & - \\
\hline 400 & 7.51 & 400 & 7.30 & 400 & - \\
\hline
\end{tabular}




\section{(E) LIST OF SYMBOLS}

1. $\Phi p$ - volume fraction of powder

2. $\Phi b$ - volume fraction of binder

3. $\Phi c$ - volume fraction of composite

4. $\rho p$ - density of powder

5. $\rho b$ - density of binder

6. $\rho c$ - density of composite

7. $v(T, p)$ - specific volume at a given temperature and pressure

8. vo - specific volume at zero-gauge pressure, $\mathrm{p}$ - pressure,

9. C - constant, 0.0894

10. b1s, b2s, b3s, b4s, b5, b7, b8, b9 - curve-fitted coefficients

11. b1m, b2m, b3m, b4m, b5, b6 - curve-fitted coefficients

12. $\eta \mathrm{b}$ - viscosity of binder

13. $\Phi \mathrm{p}$ - volume fraction of powder

14. Фmax - maximum volume fraction

15. $\gamma$ - shear rate

16. $\tau^{*}$ - critical stress level at the transition to shear thinning

17. $n$ - power law index in the high shear rate regime 
18. $\mathrm{T}$ - temperature

19. $\mathrm{Tt}$ - volumetric transition temperature

20. T*, D1, A1 - curve-fitted coefficients

21. A2 - WLF constant, $51.6 \mathrm{~K}$ 


\section{CURRICULUM VITA}

NAME: $\quad$ Bhushan Pramod Bandiwadekar

ADDRESS: 508 S. Shelby St.

Louisville, KY - 40202

DOB: $\quad$ Mumbai, India - November 12, 1993

Education

and training: B.Eng., Mechanical Engineering University of Mumbai

2011-15

PG. Diploma, Tool Design and CAD/CAM Indo German Tool Room

2015-16

M.S., Mechanical Engineering

University of Louisville, Kentucky

2016-17

Awards: $\quad$ National Science Foundation Student Grant Recipient 2017

Professional

societies: American Institute of Powder Metallurgy 2017-2018

Publications: Influence of feedstock property for estimates and measurements on powder injection molding of lead zirconate titanate", Advances in Powder Metallurgy \& Particulate Materials 2017, pp 313-323

"Influence of feedstock property for estimates and measurements on powder injection molding of lead zirconate titanate", Powder Injection Moulding International, vol 11 no. 4, pp 86-90 